\title{
Análisis preliminar de procedencia de rocas clásticas jurásicas del valle de Huizachal, Sierra Madre Oriental: Influencia del vulcanismo sinsedimentario y el basamento cristalino
}

\author{
Igor Ishi Rubio Cisneros ${ }^{1, *}$, Juan Alonso Ramírez Fernández ${ }^{1}$, Raúl García Obregón ${ }^{1}$ \\ ${ }^{1}$ Facultad de Ciencias de la Tierra, Universidad Autónoma de Nuevo León, Carretera Linares-Cerro Prieto km 8, C. P. 67700, Linares, \\ Nuevo León, México. \\ *igor_rubio@yahoo.com
}

\begin{abstract}
Resumen
El valle de Huizachal es el cañón más austral que corta al Anticlinorio Huizachal-Peregrina de la Sierra Madre Oriental (Ciudad Victoria, Tamaulipas). En el presente estudio, se realizó el estudio petrológico preliminar de las unidades volcánicas y clásticas (lechos rojos: lutitas, limolitas, areniscas y conglomerados) que conforman a las rocas jurásicas de las Formaciones La Boca y La Joya. La Formación La Boca ha sido dividida en dos miembros, el más antiguo se encuentra con echados casi verticales, mientras que el superior es sub-horizontal. Estos son suprayacidos por los lechos rojos de la Formación La Joya. El relleno sedimentario consiste de depósitos aluviales y fluviales distribuidos de manera irregular, con una alta influencia de detritos volcánicos derivados de rocas ígneas emplazadas a lo largo de la base y parte media de la sección geológica medida. Las rocas volcánicas comprenden derrames de lavas basáltico-andesíticas y depósitos piroclásticos en la base y domos riolíticos y complejos depósitos volcaniclásticos (lahares, ignimbritas y otros tipos de tobas) hacia la parte superior de la secuencia. El estudio petrográfico de los componentes principales de las areniscas de ambas formaciones ha revelado la presencia de dos petrofacies. La primera corresponde al miembro basal de la Formación La Boca, mientras que la segunda involucra al miembro superior de la misma formación y a la Formación La Joya. La primera petrofacies está constituida por arenitas feldespáticas a líticas depositadas en zonas de arco transicional con tendencia a arco disectado. La segunda petrofacies se compone de arenitas líticas depositadas en un ambiente de orógeno reciclado. Las petrofacies reflejan una procedencia a partir del contenido de cuarzo en rocas metamórficas de grado bajo a medio (esquistos, serpentinitas y gneises) y rocas ígneas (riolitas). Adicionalmente, la distinción de líticos metamórficos validó la procedencia de detritos del basamento del NE de México. La diferenciación del contenido lítico volcánico a partir de la caracterización textural ha confirmado la posición normal de la secuencia, y ha demostrado la influencia del reciclamiento y/o exhumación de la secuencia volcánica, sedimentaria y cristalina del basamento. La composición de las areniscas en el valle del Huizachal varía de base a techo debido a la compleja historia tectónica de la región, que involucra la presencia del basamento cristalino heterogéneo del Precámbrico-Paleozoico, el régimen extensional asociado a la apertura del Golfo de México y la instauración de un arco volcánico jurásico.
\end{abstract}

Palabras clave: Procedencia, Formación La Boca, Formación La Joya, lechos rojos, valle de Huizachal.

\section{Abstract}

The Huizachal valley is the southernmost canyon that cuts the Huizachal-Peregrina Anticlinorium of the Sierra Madre Oriental (Ciudad Victoria, Tamaulipas). In this work, a preliminary petrological study of the volcanic and clastic (red beds: shales, siltstones, sandstones, and conglomerates) units of the Jurassic La Boca and La Joya Formations was carried out. The La Boca Formation was divided into two members: the older member has a near-vertical dip, while the upper member is sub-horizontal. These members are overlain by red beds of the La Joya Formation. The sedimentary fill consists of alluvial and fluvial deposits distributed irregularly, 
with a high influence of volcanic detritus derived from igneous rocks emplaced at the base and in the middle parts of the measured geological profile. The volcanic rocks consist of basaltic-andesitic lava flows and pyroclastic deposits at the base and rhyolitic domes and complex pyroclastic deposits (lahars, ignimbrites, and other types of tuffs) in the upper part of the sequence. Petrographic analysis of the main constituents of the sandstones from both formations reveals the presence of two petrofacies. The first one corresponds to the La Boca Formation lower member, and the second to the La Boca Formation upper member and the La Joya Formation. The first petrofacies corresponds to feldespathic to lithic arenites deposited in a transitional arc zone with a tendency to dissected arc. The second petrofacies comprises lithic arenites deposited in a recycled orogen setting. The petrofacies reflect a provenance by means of the quartz content in low to mid-grade metamorphic rocks (schists, sepentinites, and gneisses), and igneous rocks (rhyolites). Moreover, the recognition of metamorphic lithics validates the provenance of detritus from the NE Mexico basement. The differentiation of the volcanic lithic content based on its textural characterization has confirmed the normal position of the sequence, and also demonstrated the influence of recycling and/or exhumation of the volcanic, sedimentary and crystalline basement sequence. The composition of the Huizachal valley sandstones varies from base to top due the complex regional tectonic history that involves the presence of a heterogeneous crystalline Precambrian to Paleozoic basement, the extensional regime related to the opening of the Gulf of Mexico, and the emplacement of a Jurassic volcanic arc.

Keywords: Provenance, La Boca Formation, La Joya Formation, red beds, Huizachal valley.

\section{Introducción}

El Anticlinorio Huizachal-Peregrina (AHP, Figura 1) es una estructura laramídica de la Sierra Madre Oriental, cuyo núcleo representa una ventana geológica en la que afloran el basamento y las unidades sedimentarias que lo sobreyacen. Esto permite analizar la evolución de las secuencias sedimentarias y la estructura misma. Hasta el momento, existen interrogantes sobre la génesis de los sedimentos clásticos, en especial sobre la procedencia de los componentes constructores de las areniscas, la cual ha sido resuelta utilizando como base la información petrográfica. Los modelos de procedencia basados en Dickinson (1970) y los modificados por colaboradores (e.g. Ingersoll, 1990), realizados en ambientes geológicos actuales, han representado un gran aporte a la petrología de rocas clásticas. Se proponen como herramientas para la discriminación de firmas detríticas de ambientes tectónicos contrastantes a escala continental, incluyendo las de márgenes pasivos y zonas de subducción. Sin embargo, es bien conocido que los escenarios naturales pueden resultar en petrofacies incongruentes, por la interacción y heterogeneidad de los procesos geológicos. Por esta razón, el uso de la petrología sedimentaria, e ígnea, puede ser una gran ayuda al momento de postular una hipótesis sobre la procedencia, en especial una de origen magmático.

Aún cuando las observaciones y relaciones de campo sugieren una influencia directa del emplazamiento riolítico sobre las areniscas jurásicas del AHP, es imprescindible manejar un dictamen más elaborado que valide dicha interpretación. Es por esto que el presente estudio se desarrolla bajo una metodología que aborda el estudio de procedencia de los sedimentos clásticos en función de un análisis cualitativo y cuantitativo de los componentes principales que constituyen a la roca fuente. Lo anterior, con el fin de entender la historia de los depósitos, así como de determinar las áreas fuentes potenciales que en algún momento sirvieron como aporte de detritos a las areniscas del valle de Huizachal.

La información petrográfica recabada es utilizada para documentar la composición detrítica y procedencia de rocas epiclásticas relacionadas a un ambiente geológico de arco volcánico y de la subsecuente cubierta sedimentaria. Los controles estratigráficos alogenéticos como la subsidencia y exhumación de las áreas fuentes potenciales, el intemperismo $\mathrm{y}$ reciclaje de las fuentes tienen un efecto preponderante en la firma petrográfica (Johnson, 1991). El volumen de material volcánico emergente dictamina la distribución en superficie del material, influenciando la sedimentación. El estilo de emplazamiento rige el control topográfico y de relieve del área fuente. De esta forma la tectónica y la subsidencia en áreas adyacentes favorecen zonas de depósitos contrastantes. El clima es un factor importante, pero difícil de evaluar, dada la edad y condición de los depósitos en cuestión. Asociado a esto, se presentan ajustes en el drenaje local y la disponibilidad hídrica, que determinaron la calidad y escala del transporte; la clasificación y madurez de los sedimentos, así como el sistema deposicional asociado. Esto permite generar una comparación más detallada de las características petrográficas de los minerales ligeros entre las rocas volcánicas y la cubierta volcanosedimentaria que constituyen a los lechos rojos.

Las rocas analizadas pertenecen a la secuencia de los lechos rojos y rocas volcánicas asociadas, clásicamente descritos como Grupo Huizachal (Mixon et al., 1959; Carrillo-Bravo, 1961; García-Obregón, 2008). La Formación La Boca está compuesta por una serie de productos volcánicos (flujos y domos) y volcaniclásticos (lahares, ignimbritas y otros tipos de tobas), los cuales están interestratificados con areniscas y rocas epiclásticas (lutitas, limolitas, areniscas y conglomerados). Por otra parte, la Formación La Joya, que la sobreyace, comprende lechos rojos influenciados por componentes derivados de la secuencia volcanosedimentaria subyacente y del basamento. 

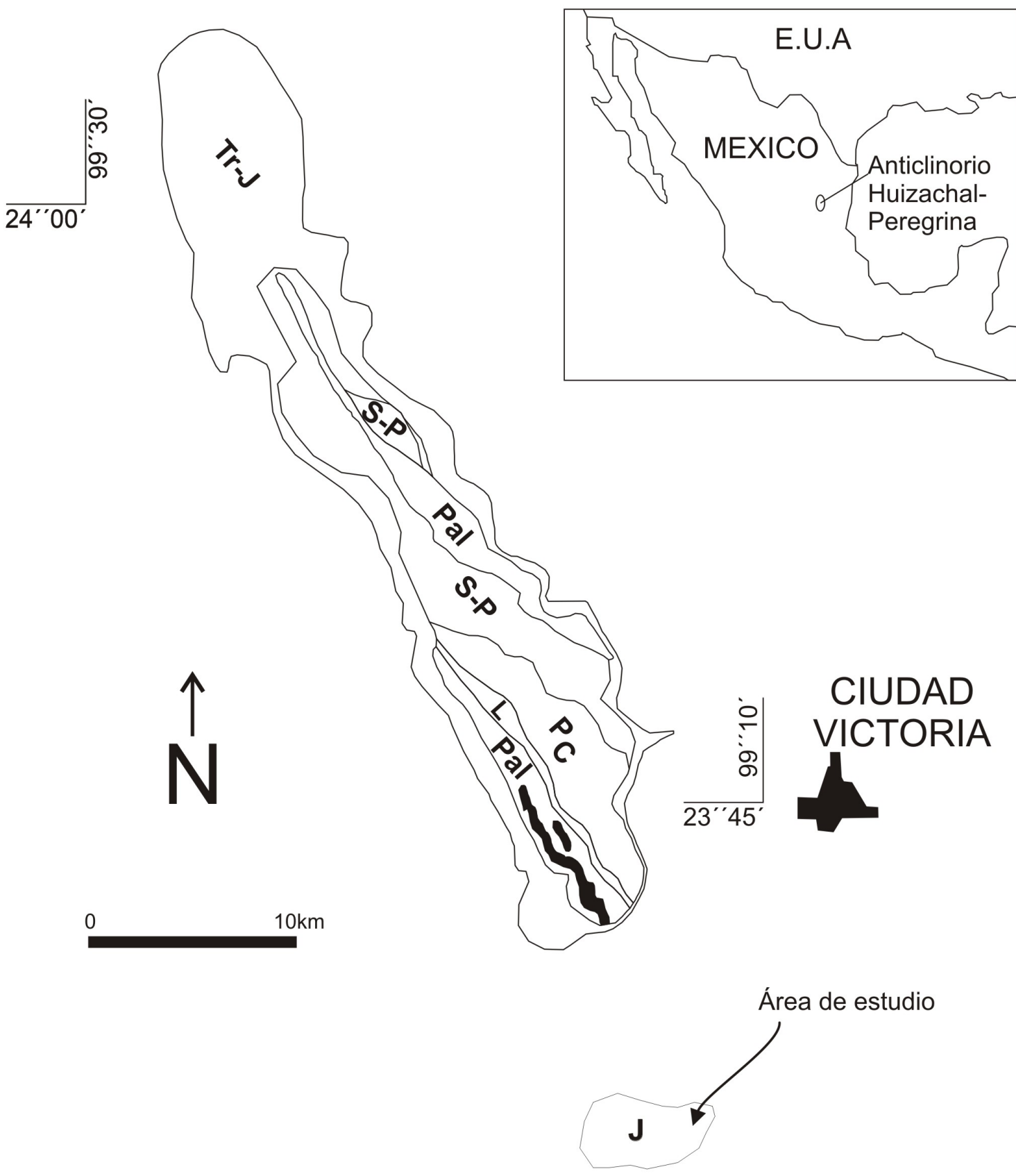

Figura 1. Localización del área de trabajo, valle de Huizachal. Leyenda extraída y adaptada de las unidades de Gursky (1996) y García-Obregón (2008). Se muestra el núcleo del Anticlinorio Huizachal Peregrina, con las unidades Pc: Gneis Novillo, Precámbrico; Pal: Esquisto Granjeno y serpentinita (en negro),

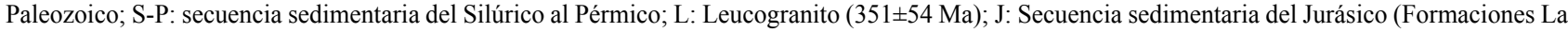
Boca y La Joya); Tr-J: Secuencia sedimentaria del Triásico-Jurásico (Formaciones El Alamar, La Boca, La Joya, Novillo, Olvido, La Casita, Taraises).

Las rocas anteriormente descritas corresponden a la cubierta que suprayace al basamento Precámbrico y Paleozoico en el Noreste de México (Barboza-Gudiño et al., 2010, 2011) y que representan el inicio de la transgresión mesozoica.

\section{Contexto geológico local}

El valle de Huizachal es uno de los cañones que corta al AHP, que a su vez forma parte del cinturón de pliegues y cabalgaduras de la Sierra Madre Oriental (SMO), en el estado de Tamaulipas. El valle de Huizachal ha sido 
erosionado desde el Terciario, exponiendo desde los lechos rojos del Grupo Huizachal hasta las calizas de cuenca de la Formación Tamaulipas Superior (Albiano). Esta área se encuentra a $26 \mathrm{~km}$ al SW de Ciudad Victoria, Tamaulipas, y queda comprendida entre las coordenadas UTM 14472600 E a 14479500 E, y $2607000 \mathrm{~N}$ a $2611000 \mathrm{~N}$, cubriendo una superficie aproximada de $20 \mathrm{~km}^{2}$ (Figura 2).

El AHP presenta un basamento heterogéneo que expresa una historia geológica muy complicada. Se compone de una constelación de unidades muy disímiles en origen y edad. La unidad más antigua es el Gneis Novillo (GN), que tiene edades de alrededor $\sim 1 \mathrm{Ga}$, y constituye un complejo metamórfico formado por rocas metasedimentarias intrusionadas por cuerpos gabro-anortosíticos ( 1010-1035 Ma y 1115-1235 Ma; Cameron et al., 2004). Esta unidad fue afectada por deformación polifásica y metamorfismo en facies granulíticas (990 $\pm 5 \mathrm{Ma}$; Cameron et al., 2004) y un emplazamiento anortosítico pegmatítico post-tectónico de $978 \pm 13 \mathrm{Ma}$ (análisis de U-Pb en zircones; Cameron et al., 2004). Este complejo es cortado, al menos, por dos enjambres de diques máficos (550 Ma; Keppie et al., 2006). Según los trabajos más recientes, forma parte de Oaxaquia (Ortega-Gutiérrez et al., 1995; Keppie et al., 2004), habiéndose descartado una relación con Laurencia durante su formación y, a la vez, con el desplazamiento de la propuesta Falla Mojave-Sonora (Anderson y Silver, 2005).

Sobrayaciendo discordantemente al Gneis Novillo aflora una sucesión no metamorfizada de sedimentos marinos paleozoicos que presentan en su base rocas clásticas formadas en ambiente someros del Silúrico Medio (Wenlockiano Temprano a Medio, 428-423 Ma; Gradstein et al., 2004), con fauna de afinidad con Gondwana (Stewart et al., 1999). Esta secuencia está cubierta discordantemente por areniscas y lutitas del Misisípico Inferior (Osageano temprano; 351-342 Ma; Okulitch, 2002) con contenido faunístico de afinidad con Laurencia. Estas rocas están sobreyacidas por flujos bandeados de riolita con una edad de $334 \pm 34 \mathrm{Ma}$ (edad por U-Pb en zircones; Stewart et al., 1999), y discordantemente cubierta por turbiditas pérmicascarboníferas (Wolfcampiano y Leonardiano, 299-271 Ma; Gradstein et al., 2004) y un flysch volcaniclástico (Gursky y Michalzik, 1989).

Por contacto de falla afloran, en particular en los cañones Novillo y Caballeros del mismo AHP, al menos dos grandes bloques orientados NW-SE de otra unidad metamórfica de edad paleozoica y formada bajo condiciones de esquistos verdes. Esta unidad, definida como Esquisto Granjeno (Carrillo-Bravo, 1961), está compuesta de rocas metavolcánicas (tobas) y metasedimentarias (pelitas y psammitas principalmente) con lentes o escamas de serpentinitas y metagabros. La edad de esta unidad es de 430-300 Ma (Dowe et al., 2005; Nance et al., 2007). Un cinturón permo-triásico (287 a $232 \mathrm{Ma}$; Bartolini et al., 1999; Torres et al., 1999) de intrusivos de diorita y granodiorita no metamorfizados, corta a las unidades previamente descritas a lo largo de una traza NW-SE que se extiende desde la Sierra Madre Oriental pasando por el Bloque de Coahuila hasta el Cratón de Norte América.

El estadio de rift dio inicio durante el Triásico Tardío con un régimen extensivo del Golfo de México. Sin embargo, hasta la fecha no se han reportado rocas con edades probadas del Triásico Tardío en la región de estudio, donde este episodio de apertura corresponde al Jurásico Temprano, representado por los lechos rojos de las Formaciones
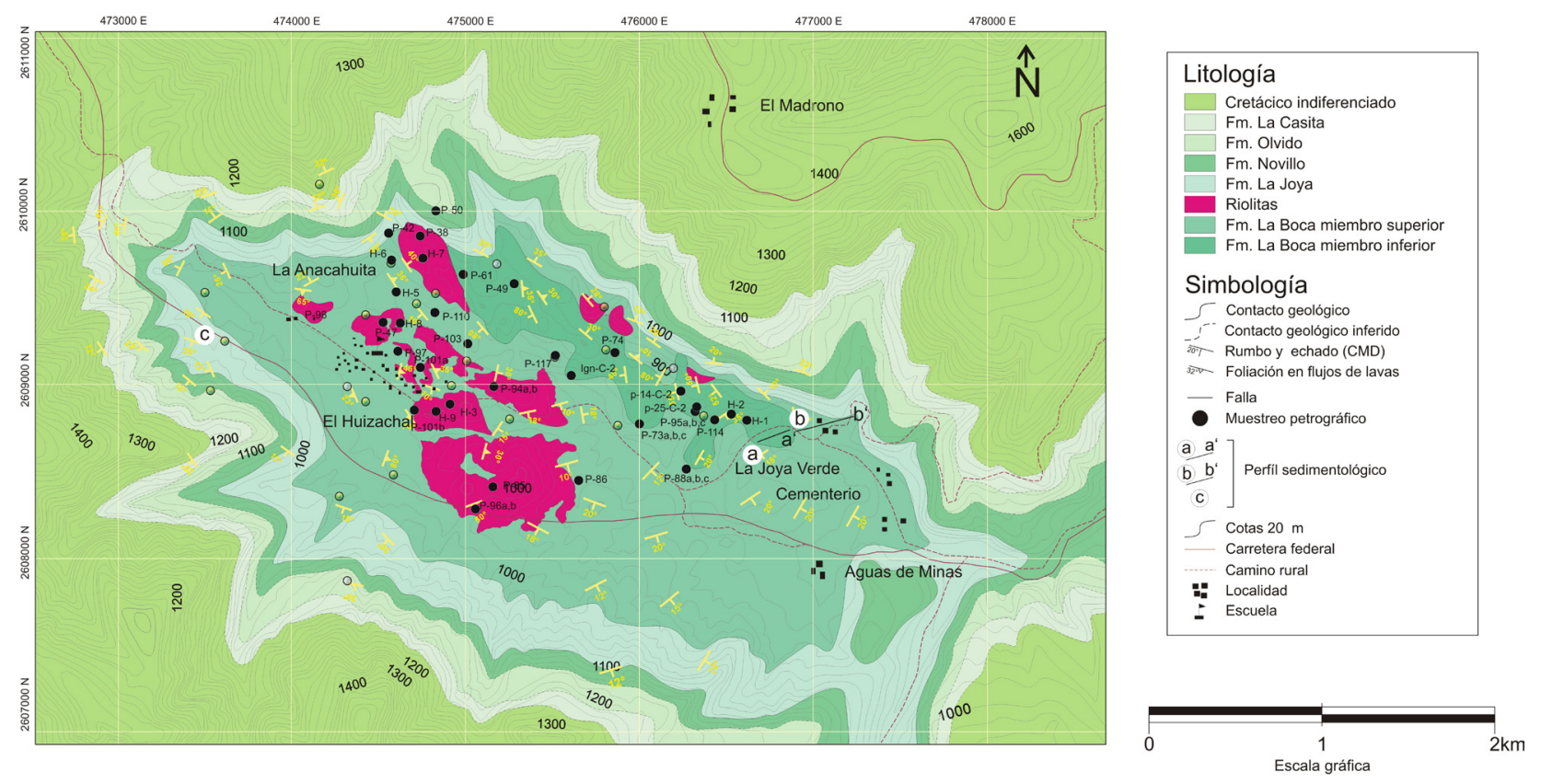

Figura 2. Mapa geológico del valle de Huizachal (modificado de García-Obregón, 2008). 
Huizachal (Formación El Alamar en el sentido de BarbozaGudiño, 2008), La Boca y La Joya. Esta secuencia de capas rojas incluye diferentes litofacies caracterizadas por ciclos granodecrecientes que muestran patrones de baja sinuosidad de ríos trenzados (Michalzik, 1991; Rueda-Gaxiola et al., 1999). Estos sistemas fluviales pueden ser simples o compuestos, y terminales o de tránsito, según sean las facies y la localidad del depósito. Los lechos rojos se extienden a lo largo de la Sierra Madre Oriental, desde el norte en Galeana, Nuevo León, con depósitos del Triásico Tardío (Michalzik, 1988; Barboza-Gudiño, 2008; Rubio-Cisneros, 2008) hasta el sur en Ciudad Victoria, con secuencias del Jurásico Temprano a Medio (Fastovsky et al., 2005).

Los lechos rojos de la Formación La Boca, en el valle de Huizachal (Figura 2), al suroeste de Ciudad Victoria (Mixon et al., 1959) están representados por depósitos de flujos de masa por gravedad afectados por volcanismo sinsedimentario relacionado con el arco activo durante el Jurásico Temprano (Fastovsky et al., 2005). Recientes interpretaciones sugieren que los lechos rojos de esta unidad pueden ser divididos en dos miembros. El miembro inferior corresponde al Jurásico Temprano, que Fastovsky et al. (2005) dividieron como la unidad VES (volcanicepiclastic suite), está orientado NW/SE con buzamientos semiverticales $\left(\sim 75^{\circ}\right)$ y consiste de intercalaciones de materiales volcánicos (flujos de lava), volcaniclásticos (flujos piroclásticos, tobas, tobas cristalinas, lahares, ignimbritas) y sedimentarios (limolitas, lutitas, areniscas y conglomerados). García-Obregón (2008) describió estos paquetes basales como Formación Huizachal y les asignó informalmente una edad triásica, basado solamente en su posición estratigráfica. En este trabajo consideramos estos paquetes como el miembro inferior de la Formación $\mathrm{La}$ Boca (Figuras 2 y 3 ).

La posición estructural del miembro inferior pudo haber sido provocada por fallas lístricas (tipo roll over) durante los episodios extensionales durante la ruptura de Pangea y reactivadas durante la fase compresiva laramídica (Zhou et al., 2006). La unidad superior, descrita por Fastovsky et al. (2005) como una "sedimentary suite", yace de manera horizontal a subhorizontal y está constituida por un paquete conglomerático basal sobreyacido por una sucesión de rocas volcánicas, volcaniclásticas y clásticas. En este trabajo se describe esta secuencia como miembro superior de la Formación La Boca (Figura 2 y 3). En este miembro destaca la presencia de domos y flujos riolíticos, que se encuentran sobreyaciendo, interdigitados y subyaciendo las secuencias clásticas, dependiendo del nivel estratigráfico. En este miembro se aprecian estratos de conglomerados $\mathrm{y}$ areniscas que han sido parcialmente silicificados por fluidos hidrotermales, ya que las condiciones de porosidad fueron propicias para estos procesos que están relacionadas directamente a las etapas finales de las extrusiones riolíticas. Los miembros sedimentarios de la Formación La Boca muestran un alto contenido de feldespatos y una escasa matriz (García-Obregón, 2008).

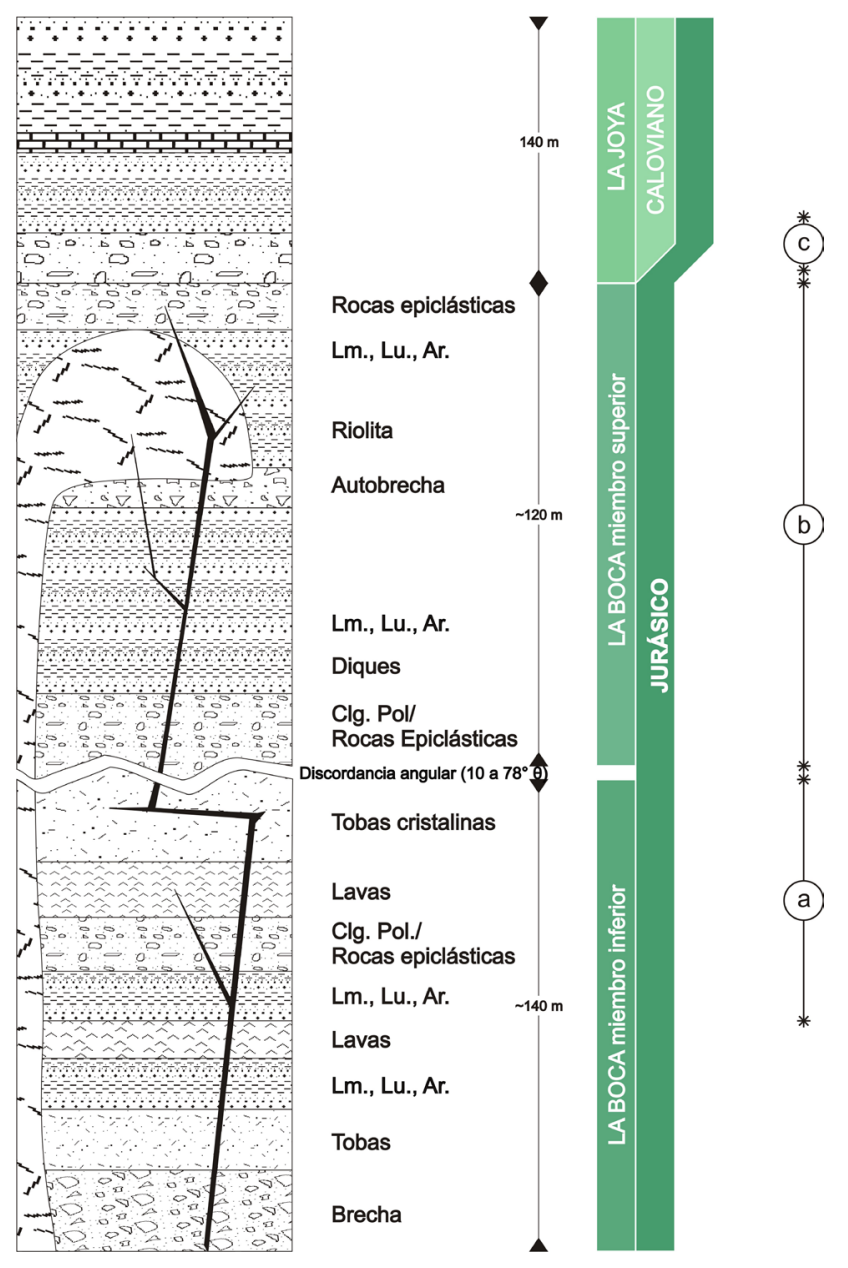

Figura 3. Columna litoestratigáfica simplificada de las Formaciones La Boca y La Joya en el valle de Huizachal (García-Obregón, 2008). Los códigos a la derecha corresponden a las secciones estratigáficas documentados en la Figura 2. Lm: limo, Lu: lutita, Ar: arenisca, Clg. Pol.: conglomerado poligmítico, $\theta$ : buzamiento del plano de discordancia. El intrusivo en la sección representa un cuerpo de composición riolítica. Las líneas gruesas de color negro representan diques.

Los domos riolíticos varían físicamente hacia sus periferias, ya que en su parte central la foliación es completamente vertical, misma que se horizontaliza hacia los flancos hasta guardar una orientación similar al de las rocas clásticas. En la parte central de los mismos aparece una fuerte alteración feldespática, mientras que en algunas zonas, se manifiestan esferulitas producto de devitrificación.

La Formación La Joya (Calloviano; Mixon et al., 1959) sobreyace en contacto erosivo a la Formación La Boca, y consiste en rocas sedimentarias siliciclásticas no marinas a marino- marginales, con intercalaciones delgadas de calizas hacia su parte superior (Michalzik, 1988; GarcíaObregón, 2008). Estos lechos rojos incluyen limolitas, lutitas, areniscas y conglomerados que se originaron como el relleno continuo de cuencas relacionadas a la formación del rift. La Formación La Joya es en parte correlacionable con los depósitos evaporíticos de la Formación Minas 
Viejas de la transgresión marina en el NE de México para el Calloviano (Salvador, 1987; Goldhammer y Johnson, 2001). Los depósitos de esta formación marcan el inicio, durante el Jurásico Tardío, de la transgresión marina que comprende la secuencia clástica y carbonatada para el Noreste de México (Goldhammer, 1999).

De acuerdo a Zhou et al. (2006), el AHP estuvo sujeto durante el Triásico al Jurásico Medio a apertura y durante el Cretácico Superior al Cenozoico Temprano a un acortamiento tectónico. En el AHP se registran dos fases de deformación. La primera es de "piel delgada" (thin-skin) y la segunda de "piel gruesa" (thick-skin). Durante la fase de "piel delgada" los estratos del Jurásico Superior al Cretácico se acomodaron por una serie de pliegues y cabalgaduras. Durante la fase de "piel gruesa" el basamento fue levantado a lo largo de fallas reactivadas, deformándose internamente.

La región del valle de Huizachal ha sido objeto de diversos estudios, sin embargo no se había llevado a cabo ningún análisis detallado enfocado a la petrología de las unidades clásticas y su relación con los cuerpos volcánicos que se emplazaron de manera sindeposicional. Esta investigación busca contribuir a la comprensión petrológica de las rocas que afloran en el Anticlinorio Huizachal Peregrina (AHP) y su asociación a una historia geológica en términos de la procedencia para su depósito, durante el Jurásico en el Noreste de México. Para este fin, se condujeron trabajo de campo y análisis petrográficos, tanto de rocas volcánicas como de volcaniclásticas, que constituyen a los miembros inferior y superior de la Formación La Boca. Este estudio examina el registro volcanosedimentario para determinar la naturaleza de los depósitos de lechos rojos continentales en el Noreste de México, asociados a la influencia del vulcanismo contemporáneo al depósito en la localidad del valle de Huizachal.

\section{Litología}

A continuación se describen las principales litologías de las rocas volcánicas y volcaniclásticas del valle de Huizachal de los miembros inferior y superior de la Formación La Boca (Tablas 1 y 2; Figuras 2 y 4). Por otra parte, y con el objeto de caracterizar a las rocas clásticas que afloran en el área de estudio e identificar su procedencia, fueron seleccionadas siete muestras de areniscas (con granulometría aproximada de arenas medias) en puntos específicos dentro del valle de Huizachal (Tablas 3 y 4; Figuras 3 y 5). Estas muestras fueron tomadas de horizontes de rocas sedimentarias que se interdigitan con las secuencias volcánicas. Para un análisis más confiable de ambos tipos de rocas, se revisaron muestras, en la medida de lo posible, libres de intemperismo.

\subsection{Rocas volcánicas y volcaniclásticas}

\subsubsection{Formación La Boca, Miembro Inferior}

La Formación La Boca, en su miembro inferior, contiene tanto rocas volcánicas básicas como félsicas, que contrastan con las de la Formación La Boca superior: (1) basaltos, (2) ignimbritas, (3) tobas cristalinas, y (4) pórfidos (Tabla 1 y Figura 4). A continuación se describen las características principales de cada uno.

Basaltos. Las rocas basálticas forman paquetes masivos con coloración negra a verdosa. Es frecuente observar texturas brechadas y peperíticas. Al microscopio, se presentan texturas glomeroporfídicas con matriz traquítica. Los fenocristales primarios incluyen olivino, piroxeno y plagioclasa, los cuales se encuentran parcial o totalmente sustituidos por clorita y sericita. Los bordes de los fenocristales se encuentran opacitizados, denotando

Tabla 1. Listado de muestras de rocas volcánicas y volcaniclásticas, incluyendo características petrográficas de la Formación La Boca Inferior.

\begin{tabular}{|c|c|c|c|c|}
\hline Muestra & Coordenadas & Grupo Litológico & $\begin{array}{c}\text { Características } \\
\text { Texturales }\end{array}$ & Mineralogía \\
\hline Huiz-1 & $2608814 \mathrm{~N}-14476668 \mathrm{E}$ & \multirow{4}{*}{ Basalto } & \multirow{4}{*}{$\begin{array}{l}\text { Porfirítica a } \\
\text { glomeroporfírica }\end{array}$} & \multirow{4}{*}{$\begin{array}{l}\text { Restos de olivinos y piroxenos esqueletales con bordes opacitizadios envueltos en una } \\
\text { matriz traquítica de plagioclasa alterada a clorita y sericita. }\end{array}$} \\
\hline P-95a & $2608720 \mathrm{~N}-14476712 \mathrm{E}$ & & & \\
\hline P-95b & $2608720 \mathrm{~N}-14476712 \mathrm{E}$ & & & \\
\hline P-95c & $2608720 \mathrm{~N}-14476712 \mathrm{E}$ & & & \\
\hline Huiz-2 & $2608847 \mathrm{~N}-14476590 \mathrm{E}$ & \multirow{6}{*}{ Ignimbrita } & \multirow{6}{*}{$\begin{array}{l}\text { Parcialmente orientada, } \\
\text { fluidal, porfirítica }\end{array}$} & \multirow{6}{*}{$\begin{array}{l}\text { Muestra esquirlas de vidrio, fenocristales de plagioclasas y feldespatos, con restos de } \\
\text { pómez y esferulitas de cuarzo-feldespato. Matriz microgranular. Parcialmente soldada } \\
\text { con texturas de devitrificación. Sericitización común, existe una fuerte oxidación y } \\
\text { presencia de líticos. }\end{array}$} \\
\hline P-50 & $2609880 \mathrm{~N}-14475232 \mathrm{E}$ & & & \\
\hline P-88b & $2608545 \mathrm{~N}-14476266 \mathrm{E}$ & & & \\
\hline $\mathrm{P}-88 \mathrm{c}$ & $2608545 \mathrm{~N}-14476266 \mathrm{E}$ & & & \\
\hline P-110 & $2609285 \mathrm{~N}-14475257 \mathrm{E}$ & & & \\
\hline Ign-C-2 & $2609074 \mathrm{~N}-14475632 \mathrm{E}$ & & & \\
\hline P-73a & $2608780 \mathrm{~N}-14476020 \mathrm{E}$ & \multirow{4}{*}{ Toba cristalina } & \multirow{4}{*}{$\begin{array}{l}\text { Textura fluidal } \\
\text { orientada ligeramente } \\
\text { porfirítica }\end{array}$} & \multirow{4}{*}{$\begin{array}{l}\text { Restos de fenocristales de feldespatos, plagioclasas y clinopiroxenos remplazados por } \\
\text { sericita y clorita, en una matriz cuarzofeldespática alterada. Presenta abundante } \\
\text { sanidino, líticos y un soldamiento en la matriz fina. Esquirlas de vidrio. }\end{array}$} \\
\hline $\mathrm{P}-42$ & $2609736 \mathrm{~N}-14474911 \mathrm{E}$ & & & \\
\hline P-61 & $2609448 \mathrm{~N}-14475344 \mathrm{E}$ & & & \\
\hline $\mathrm{P}-117$ & $2609080 \mathrm{~N}-14476020 \mathrm{E}$ & & & \\
\hline $\mathrm{P}-114$ & $2608815 \mathrm{~N}-14476649 \mathrm{E}$ & Pórfido riolítico & \multirow{3}{*}{$\begin{array}{l}\text { Porfídica granular } \\
\text { hipidiomórfica }\end{array}$} & Contiene fenocristales de cuarzo y feldespatos envueltos en una matriz afanítica. \\
\hline P-14-C-2 & $2608999 \mathrm{~N}-14476335 \mathrm{E}$ & \multirow{2}{*}{ Pórfido andesítico } & & \multirow{2}{*}{$\begin{array}{l}\text { Feldespatos sericitizados con fantasmas de anfíboles cloritizados envueltos en una } \\
\text { matriz cuarzofeldespática alterada. }\end{array}$} \\
\hline P-25b-C-2 & $2608910 \mathrm{~N}-14476473 \mathrm{E}$ & & & \\
\hline
\end{tabular}


Tabla 2. Listado de muestras de rocas volcánicas y volcaniclásticas, incluyendo características petrográficas de la Formación La Boca Superior.

\begin{tabular}{|c|c|c|c|c|}
\hline Muestra & Coordenadas & $\begin{array}{c}\text { Grupo } \\
\text { Litlógico }\end{array}$ & Características Texturales & Mineralogía \\
\hline Huiz-3 & $2608907 \mathrm{~N}-14474976 \mathrm{E}$ & \multirow{17}{*}{ Riolita } & \multirow{17}{*}{$\begin{array}{l}\text { Fluidal compacta, ligeramente porfirítica o bien granular } \\
\text { hipidomórfica. Con matriz cuarzofeldespática alterada. }\end{array}$} & \multirow{17}{*}{$\begin{array}{l}\text { Restos de feldespatos sericitizados, restos de anfiboles orientados, en } \\
\text { una matriz cuarzofeldespática granular alterada a sericita y calcita con } \\
\text { minerales opacos como accesorios. Con texturas de devitrificacion } \\
\text { (esferulitas) y vetilleo de cuarzo y calcita. }\end{array}$} \\
\hline Huiz-6 & $2609787 \mathrm{~N}-14474612 \mathrm{E}$ & & & \\
\hline Huiz-7 & $2609810 \mathrm{~N}-14474750 \mathrm{E}$ & & & \\
\hline Huiz-8 & $2609361 \mathrm{~N}-14474645 \mathrm{E}$ & & & \\
\hline Huiz-9 & $2608893 \mathrm{~N}-14474896 \mathrm{E}$ & & & \\
\hline P-38 & $2609877 \mathrm{~N}-14474736 \mathrm{E}$ & & & \\
\hline P-47 & $2609380 \mathrm{~N}-14474560 \mathrm{E}$ & & & \\
\hline P-49 & $2609420 \mathrm{~N}-14475745 \mathrm{E}$ & & & \\
\hline P-74 & $2609081 \mathrm{~N}-14476257 \mathrm{E}$ & & & \\
\hline P-85 & $2608370 \mathrm{~N}-14475540 \mathrm{E}$ & & & \\
\hline P-94 & $2608828 \mathrm{~N}-14475530 \mathrm{E}$ & & & \\
\hline P-96a & $2608256 \mathrm{~N}-14475067 \mathrm{E}$ & & & \\
\hline P-96b & $2608720 \mathrm{~N}-14476712 \mathrm{E}$ & & & \\
\hline P-98 & $2609475 \mathrm{~N}-14474074 \mathrm{E}$ & & & \\
\hline P-101a & $2608746 \mathrm{~N}-14475150 \mathrm{E}$ & & & \\
\hline P-111 & $2608730 \mathrm{~N}-14474920 \mathrm{E}$ & & & \\
\hline P-101b & $2608746 \mathrm{~N}-14475150 \mathrm{E}$ & & & \\
\hline Huiz-5 & $2609557 \mathrm{~N}-14474629 \mathrm{E}$ & \multirow{3}{*}{ Toba Vítrea } & Textura fluidal orientada con matriz fina oxidada & \multirow{3}{*}{$\begin{array}{l}\text { Feldespatos, líticos de material volcánico, esquirlas de vidrio, todos } \\
\text { alterados a sericita con minerales opacos, en una matriz oxidada } \\
\text { parcialmente. Presenta cristales alterados de feldespatos y plagioclasas. }\end{array}$} \\
\hline P-97 & $2609230 \mathrm{~N}-14474610 \mathrm{E}$ & & Fluidal & \\
\hline P-86 & $2608460 \mathrm{~N}-14475580 \mathrm{E}$ & & Fluidal orientada & \\
\hline P-88a & $2608545 \mathrm{~N}-14476266 \mathrm{E}$ & \multirow{2}{*}{ Epiclástica } & \multirow{2}{*}{ Microlítica orientada } & \multirow{2}{*}{$\begin{array}{l}\text { Presenta cristales alterados de feldespatos, líticos de diferentes } \\
\text { composiciones (volcánicos y sedimentarios), plagioclasas en una } \\
\text { matriz fuertemente oxidada. Contiene clastos, con cuarzo onduloso }\end{array}$} \\
\hline P-103 & $2609230 \mathrm{~N}-14475440 \mathrm{E}$ & & & \\
\hline
\end{tabular}

el hábito original. Los fantasmas de olivino y piroxeno se presentan como secciones esqueletales rómbicas y hexagonales en una matriz traquítica de plagioclasa (Figuras $4 a, b)$.

Ignimbritas. Las ignimbritas forman paquetes de menos de $1 \mathrm{~m}$ de espesor, con fragmentos líticos y pómez intemperizados. Las muestras de este grupo presentan una textura típica de ignimbrita, en la que se pueden apreciar fragmentos colapsados de pómez (fiamme) y esquirlas de vidrio, coexistiendo con feldespatos potásicos y plagioclasas. Además se presentan texturas de devitrificación con esferulitas, con cristales de cuarzo y feldespatos. La mayor parte de las muestras presentan una textura fluidal (Figuras 4c, d).

Tobas Cristalinas. Los paquetes de toba son compactos, con color verdoso a rojizo. Presentan texturas porfiríticas fluidales (Figura 4e), donde el común denominador corresponde a cristales tabulares orientados de sanidino y plagioclasas, acompañados de esquirlas de vidrio y fragmentos líticos. Muchos de estos cristales están alterados a clorita y sericita, con una matriz cuarzofeldespática oxidada. Algunas muestras de estas rocas se encuentran soldadas.

Pórfidos. Los pórfidos cortan al resto de las unidades y se emplazaron típicamente como diques discordantes, con espesores menores a los $50 \mathrm{~cm}$. Este grupo se subdivide en pórfidos riolíticos y pórfidos andesíticos. Los primeros presentan fenocristales de cuarzo y feldespatos, envueltos en una matriz afanitíca muy alterada. Los segundos consisten en feldespatos sericitizados, con fantasmas de anfíboles cloritizados, en una matriz cuarzofeldespática alterada.

\subsubsection{Formación La Boca, Miembro Superior}

La Formación La Boca en su miembro superior se compone de rocas sedimentarias continentales intercaladas con rocas volcánicas de composición más félsica que el miembro inferior. En esta parte de la secuencia, con base en la mineralogía y la textura, se pueden clasificar tres grupos de rocas volcánicas y volcaniclásticas: (1) grupo riolítico (2) grupo de tobas vítreas, y (3) grupo de epiclastitas (Tabla 2). A continuación se describen las características texturales y mineralógicas de cada grupo.

Riolitas. Estas rocas comprenden los afloramientos de los principales domos del área, que son fácilmente reconocibles en el centro del valle de Huizachal por su coloración crema, y la estructura volcánica fluidal, pseudoestratificada, esferulítica o isótropa. Las rocas riolíticas (sensu stricto) muestran una textura fluidal ligeramente porfirítica, donde los fenocristales corresponden a feldespatos altamente sericitizados y restos de anfíboles también remplazados; todo ello, en una matriz cuarzofeldespática, sericitizada y cloritizada, que se encuentra parcialmente oxidada (Figura 4f). La mayoría de las muestras presenta un fuerte vetilleo de cuarzo. También presenta esferulitas producto 

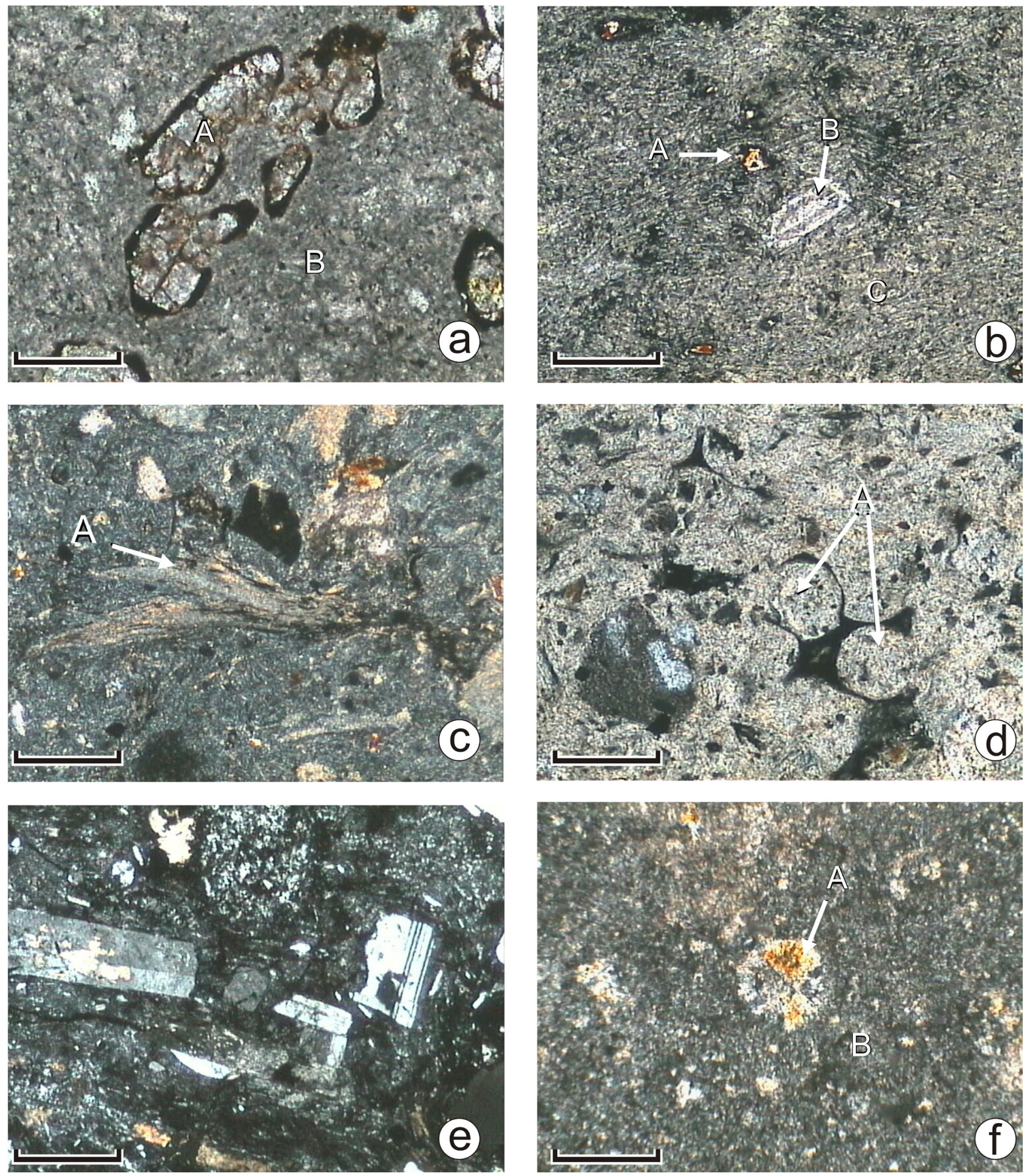

Figura 4. Fotomicrografías con nícoles cruzados de rocas volcánicas y volcaniclásticas de la Formación La Boca, Miembros Inferior y Superior. a) Muestra de basalto Huiz-1, con fantasmas de cristales esqueléticos de olivino (A), en una matriz de plagioclasa (B) parcialmente alterada a sericita. b) Muestra de basalto P-25a, con fenocristales de olivino alterados (A) y plagioclasa (B), rodeados por una matriz traquítica de plagioclasa. c) Ignimbrita Huiz-2, en donde se observa un fragmento de pómez colapsado (A), ligeramente curvado; se trata de un fiamme, producto de una explosión volcánica sumamente violenta. d) Ignimbrita Huiz-2, donde se aprecian restos de burbujas bordeadas con una película de vidrio (A), y es posible reconocer esquirlas de vidrio. e) Toba cristalina P-73a, en donde se observan cristales tabulares de feldespatos, tanto sanidino como plagioclasa, en una matriz fina de cenizas con textura fluidal. f) Riolita P-96a, con esferulitas que incluyen cristales de formación tardía (cuarzo y feldespato) (A). La matriz es cuarzofeldespática (B). En todas las fotomicrografías el canto inferior mide $4 \mathrm{~mm}$. 
de devitrificación y algunos minerales opacos ligeramente orientados. Se observan escasos microcristales de zircón, así como minerales supergénicos de cobre como malaquita, azurita, crisocola, etc.

Tobas vitreas. Las afloramientos de tobas se interestratifican con las rocas clásticas, confundiéndose fácilmente. Las tobas presentan una textura de minerales orientados y están compuestos por fragmentos alterados de feldespatos y líticos angulosos y esquirlas de vidrio, contenidos en una matriz fina fuertemente cloritizada y sericitizada. La roca original de los líticos fue probablemente una toba cristalina, que fue retrabajada posteriormente.

Rocas epiclásticas. Al igual que las tobas, las rocas epiclásticas forman estratos intercalados con las rocas sedimentarias clásticas. Están constituidas por cristales alterados de feldespatos y líticos de distintos materiales, particularmente volcánicos, pero también sedimentarios y metamórficos. En las muestras estudiadas se observan plagioclasas en una matriz fuertemente oxidada.

\subsection{Origen del Vulcanismo del valle de Huizachal}

Diversos autores han descrito las rocas volcánicas de valle de Huizachal y de localidades correlacionables formadas por secuencias pre-oxfordianas (sierras de Salinas, Charcas, y Catorce, San Luis Potosí; Aramberri y San Marcos, Nuevo León). Barboza-Gudiño et al. (2008) atribuyeron estas secuencias a un arco volcánico del Jurásico, relacionado a la margen activa del suroeste de Norte América y las correlacionaron con las unidades que constituyen a la Formación Nazas de la parte norte de los estados de Durango y Zacatecas.

Por otra parte Fastovsky et al. (2005) dataron en 189.0 $\pm 0.2 \mathrm{Ma}$ un flujo piroclástico del valle de Huizachal, por medio del método U-Pb. Aunque ellos asignaron el flujo fechado al miembro inferior, el trabajo de campo realizado en este estudio muestra que pertenece al miembro superior. Gómez-Anguiano (2001) y García-Obregón (2008) definieron, a partir de diagramas de discriminación petrotectónica, la afinidad de las riolitas con un ambiente de arco volcánico continental.

\subsection{Rocas clásticas}

\subsubsection{Muestreo y metodología de estudio}

Las muestras de areniscas fueron colectadas a lo largo de tres perfiles estratigráficos ( $\mathrm{a}, \mathrm{b}$ y c en la Figura 5). Las muestras VH-3101, VH-3102, VH-3103 y VH3104 fueron colectadas de estratos de areniscas de grano medio del miembro inferior de Formación La Boca (perfil estratigráfico a). Algunos metros arriba de la discordancia angular que separa al miembro inferior del superior, se colectó la muestra VH-3108 (perfil estratigráfico b). Las últimas muestras (VH-3110, VH-3111) se colectaron de un

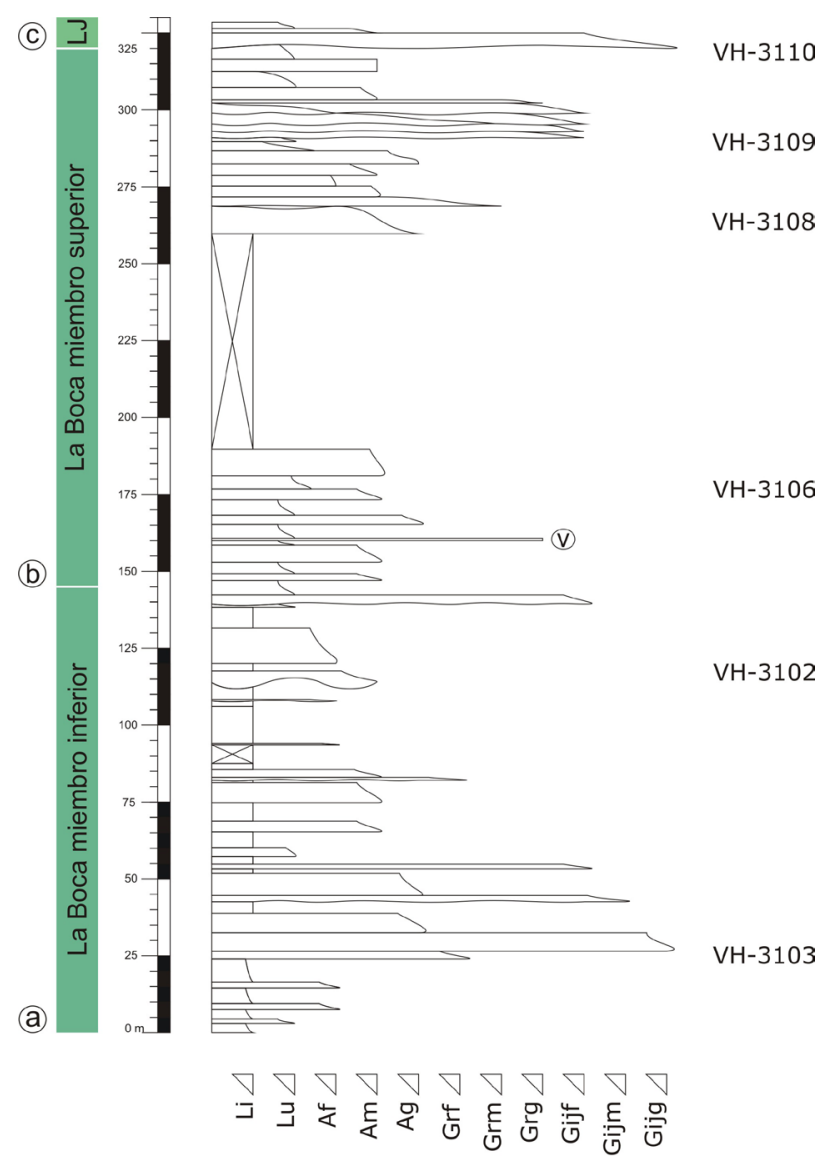

Figura 5. Perfil sedimentológico simplificado del muestreo de areniscas de las áreas a, b, y c (consultar el mapa de la Figura 2. LJ: La Joya, Li: limo, Lu: lutita, Af: arenisca fina: Am: arenisca media, Ag: arenisca gruesa, Grf: gravas finas, Grm: gravas medias, Grg: gravas gruesas, Gijf: guijas finas, Gijm: guijas medias, Gijg: guijas gruesas, V: volcánica. El número a la derecha del perfil es la clave de la muestra de arenisca colectada (e.g. VH-3106).

paquete de arenisca gruesa a conglomerado en la base de la Formación La Joya (perfil estratigráfico c).

El conteo de puntos se realizó empleando la metodología de Gazzi-Dickinson (Ingersoll et al., 1984; Tablas 3 y 4), en el que los minerales con un tamaño mayor a los $62.5 \mu \mathrm{m}$ se contaron como cristales, aun cuando se encontraran dentro de un fragmento lítico. El estudio se centró en el uso de diagramas ternarios, para discriminar las muestras analizadas en campos predeterminados por diferentes metodologías y, posteriormente, se interpretaron los resultados hacia una relación específica de rocas y ambientes/fuentes de procedencia potencial. Los índices clave que controlan la distribución de los valores dentro de los diagramas ternarios de clasificación y procedencia son cuarzo (Q), feldespatos (F) y líticos (L) (QFL+Ch de Okada, 1971; QFL y QmFLt de Dickinson et al., 1983). Los diferentes tipos de cuarzo fueron clasificados de acuerdo a lo propuesto por Blatt y Christie (1963), Basu et al. (1975) y Young (1976). La clasificación de fragmentos líticos volcánicos se basó en Dickinson (1970) y Marsaglia e 
Tabla 3. Porcentajes recalculados de los componentes principales de las areniscas colectadas en el Valle de Huizachal, utilizados en los diagramas ternarios de acuerdo a diferentes metodologías.

\begin{tabular}{|c|c|c|c|c|c|c|c|c|c|c|}
\hline \multirow[b]{2}{*}{ Formación } & \multirow[b]{2}{*}{ Muestra } & \multicolumn{3}{|c|}{$\begin{array}{c}\text { QFL } \\
\text { (Okada, 1971) }\end{array}$} & \multicolumn{3}{|c|}{ Qp2-3, Qmr, Qmo } & \multicolumn{3}{|c|}{$\mathrm{Qp}>3, \mathrm{Qmo}, \mathrm{Qmr}$} \\
\hline & & Q & $\mathrm{F}$ & $\mathrm{L}+\mathrm{Ch}$ & Qp2-3 & Qmr & Qmo & $\mathrm{Qp}>3$ & Qmo & Qmr \\
\hline La Boca Inferior & VH-3101 & 51.9 & 22.78 & 25.32 & 41.56 & 34.42 & 24.03 & 36.17 & 26.24 & 37.59 \\
\hline La Boca Inferior & VH-3102 & 46.43 & 22.45 & 31.12 & 35.57 & 28.19 & 36.24 & 25.58 & 41.86 & 32.56 \\
\hline La Boca Inferior & VH-3103 & 20.1 & 43.51 & 36.39 & 17.74 & 35.48 & 46.77 & 25 & 42.65 & 32.35 \\
\hline La Boca Inferior & VH-3104 & 19.64 & 32.91 & 47.45 & 24.07 & 35.19 & 40.74 & 35.94 & 34.38 & 29.69 \\
\hline La Boca Superior & VH-3108 & 65.28 & 2.33 & 32.38 & 13.11 & 55.74 & 31.15 & 30.26 & 25 & 44.74 \\
\hline La Joya & VH-3110 & 62.76 & 5.87 & 31.38 & 17.53 & 38.14 & 44.33 & 24.53 & 40.57 & 34.91 \\
\hline La Joya & VH-3111 & 66.75 & 10.39 & 22.86 & 15.27 & 47.78 & 36.95 & 23.89 & 33.19 & 42.92 \\
\hline $\mathrm{Pf}_{1 \text { MEDIA }}$ & & 34.52 & 30.41 & 35.07 & 29.74 & 33.32 & 36.95 & 30.67 & 36.28 & 33.05 \\
\hline $\mathrm{Pf}_{1 \text { DES. EST }}$ & & 17.059 & 9.99 & 9.41 & 10.8 & 3.45 & 9.63 & 6.22 & 7.66 & 3.3 \\
\hline $\mathrm{Pf}_{2 \text { MEDIA }}$ & & 64.93 & 6.2 & 28.87 & 15.3 & 47.22 & 37.47 & 26.23 & 32.92 & 40.85 \\
\hline $\mathrm{Pf}_{2}$ DES. EST & & 2.02 & 4.03 & 5.23 & 2.21 & 8.81 & 6.61 & 3.51 & 7.79 & 5.23 \\
\hline
\end{tabular}

\begin{tabular}{|c|c|c|c|c|c|c|c|c|c|c|}
\hline \multirow[b]{2}{*}{ Formación } & \multirow[b]{2}{*}{ Muestra } & \multicolumn{3}{|c|}{$\begin{array}{c}\text { Lm,Lv,Ls } \\
\text { (Ingersoll y Suczek, 1979) }\end{array}$} & \multicolumn{3}{|c|}{$\begin{array}{c}\text { Lvf,Lvmi,Lvl } \\
\text { (Marsaglia e Ingersoll, 1992) }\end{array}$} & \multicolumn{3}{|c|}{$\begin{array}{c}\text { QFL } \\
\text { (Dickinson y Suczek, 1979) }\end{array}$} \\
\hline & & $\mathrm{Lm}$ & $\mathrm{Lv}$ & Ls & Lvf & Lvmi & Lvl & Q & $\mathrm{F}$ & $\mathrm{L}$ \\
\hline La Boca Inferior & VH-3101 & 12.24 & 72.45 & 15.31 & 36.62 & 60.56 & 2.82 & 52.16 & 22.9 & 24.94 \\
\hline La Boca Inferior & VH-3102 & 21.49 & 57.02 & 21.49 & 71.01 & 21.74 & 7.25 & 46.55 & 22.51 & 30.95 \\
\hline La Boca Inferior & VH-3103 & 12.68 & 57.75 & 29.58 & 43.9 & 51.22 & 4.88 & 20.15 & 43.62 & 36.22 \\
\hline La Boca Inferior & VH-3104 & 3.33 & 82.22 & 14.44 & 12.16 & 87.84 & 0 & 19.95 & 33.42 & 46.63 \\
\hline La Joya & VH-3110 & 24.27 & 51.46 & 24.27 & 41.51 & 33.96 & 24.53 & 66.13 & 6.18 & 27.69 \\
\hline La Joya & VH-3111 & 37.31 & 40.3 & 22.39 & 18.52 & 81.48 & 0 & 70.6 & 10.99 & 18.41 \\
\hline $\mathrm{Pf}_{1 \text { MEDIA }}$ & & 12.44 & 67.36 & 20.2 & 40.92 & 55.34 & 3.74 & 34.7 & 30.61 & 34.68 \\
\hline $\mathrm{Pf}_{1 \text { DES. EST }}$ & & 7.41 & 12.19 & 6.99 & 24.22 & 27.26 & 3.08 & 17.07 & 10.04 & 9.2 \\
\hline $\mathrm{Pf}_{2 \text { MEDIA }}$ & & 30.2 & 48.58 & 21.22 & 23.1 & 68.73 & 8.18 & 68.85 & 6.55 & 24.6 \\
\hline $\mathrm{Pf}_{2 \text { DES. EST }}$ & & 6.6 & 7.29 & 3.77 & 16.61 & 30.46 & 14.16 & 2.39 & 4.26 & 5.36 \\
\hline
\end{tabular}

\begin{tabular}{|c|c|c|c|c|c|c|c|c|c|c|}
\hline \multirow[b]{2}{*}{ Formación } & \multirow[b]{2}{*}{ Muestra } & \multicolumn{3}{|c|}{$\begin{array}{c}\text { Qm,F,L } \\
\text { (Dickinson et al ., 1983) }\end{array}$} & \multicolumn{3}{|c|}{$\begin{array}{c}\text { Qm,P,K } \\
\text { (Marsaglia, 1991) } \\
\end{array}$} & \multicolumn{3}{|c|}{$\begin{array}{c}\text { Qp,Lvm,Lsm } \\
\text { (Ingersoll y Suczeck, 1979) }\end{array}$} \\
\hline & & Qm & $\mathrm{F}$ & $\mathrm{L}$ & $\mathrm{Qm}$ & $\mathrm{P}$ & $\mathrm{K}$ & Qp & Lvm & Lsm \\
\hline La Boca Inferior & VH-3101 & 32.37 & 32.37 & 35.25 & 50 & 45 & 5 & 53 & 33.64 & 13.36 \\
\hline La Boca Inferior & VH-3102 & 31.48 & 28.85 & 39.67 & 52.17 & 46.74 & 1.09 & 39.45 & 37.16 & 23.39 \\
\hline La Boca Inferior & VH-3103 & 14.01 & 46.98 & 39.01 & 22.97 & 77.03 & 0 & 16.37 & 57.89 & 25.73 \\
\hline La Boca Inferior & VH-3104 & 11.71 & 36.86 & 51.43 & 24.12 & 70.59 & 5.29 & 16.67 & 71.3 & 12.04 \\
\hline La Boca Superior & VH-3108 & 59.33 & 3.36 & 37.31 & 94.64 & 4.76 & 0.6 & 45.15 & 32.04 & 22.82 \\
\hline La Joya & VH-3110 & 55.94 & 8.04 & 36.01 & 87.43 & 7.65 & 4.92 & 42.57 & 30.2 & 27.23 \\
\hline La Joya & VH-3111 & 61.65 & 14.34 & 24.01 & 81.13 & 14.15 & 4.72 & 50.9 & 19.16 & 29.94 \\
\hline $\mathrm{Pf}_{1 \text { MEDIA }}$ & & 22.39 & 36.27 & 41.34 & 37.32 & 59.84 & 2.85 & 31.37 & 50 & 18.63 \\
\hline $\mathrm{Pf}_{1 \text { DES. EST }}$ & & 11.05 & 7.86 & 7 & 15.93 & 16.36 & 2.7 & 18.02 & 17.78 & 6.94 \\
\hline $\mathrm{Pf}_{2 \mathrm{MEDIA}}$ & & 58.97 & 8.58 & 32.45 & 87.74 & 8.85 & 3.41 & 46.21 & 27.13 & 26.66 \\
\hline $\mathrm{Pf}_{2 \text { DES. EST }}$ & & 2.87 & 5.51 & 7.33 & 6.76 & 4.81 & 2.44 & 4.26 & 6.96 & 3.6 \\
\hline
\end{tabular}

$\begin{array}{ccc}\mathrm{Q} & = & \text { Total de granos de cuarzo } \\ \mathrm{Qm} & = & \text { Granos monocristalinos de cuarzo } \\ \mathrm{Qmr} & = & \text { Cuarzo monocristalino recto } \\ \mathrm{Qmo} & = & \text { Cuarzo monocristalino onduloso } \\ \mathrm{Qp} & = & \text { Granos policristalinos de cuarzo } \\ \mathrm{Qp2-3} & = & \text { Grano policristalino de cuarzo con } 2-3 \text { unidades de } \\ & & \text { cristal por grano } \\ \mathrm{Qp}>3 & = & \text { Grano policristalino de cuarzo con }>3 \text { unidades de } \\ \mathrm{F} & = & \text { cristal por grano } \\ \mathrm{P} & = & \text { Fetal de granos feldespáticos } \\ \mathrm{K} & = & \text { Feldespato pódico } \\ \mathrm{Pf} & = & \text { Petrofacies }\end{array}$

$\begin{array}{ccc}\mathrm{L} & = & \text { Total de granos líticos } \\ \mathrm{Lm} & = & \text { Total de granos líticos metamórficos } \\ \mathrm{Lv} & = & \text { Total de granos líticos volcánicos } \\ \mathrm{Ls} & = & \text { Total de granos líticos sedimentarios } \\ \mathrm{Lvf} & = & \text { Líticos volcánicos con textura felsítica } \\ \mathrm{Lvmi} & = & \text { Líticos volcánicos con textura microlítica } \\ \mathrm{Lvl} & = & \text { Líticos volcánicos con textura tipo lathwork } \\ \mathrm{Lvm} & = & \text { Granos líticos volcánicos hipabisales y metamórficos } \\ \mathrm{Lms} & = & \text { Líticos sedimentarios y metasedimentarios } \\ \mathrm{Ch} & = & \text { Pedernal }(\text { chert }) \\ \text { DES. EST. } & = & \text { Desviación estándar }\end{array}$


Tabla 4. Conteo original de los componentes principales de las areniscas colectadas en el Valle de Huizachal.

\begin{tabular}{|c|c|c|c|c|c|c|c|c|c|c|c|c|c|}
\hline & Parámetro & $\mathbf{Q}$ & Qm & Qmr & Qmo & $Q \mathbf{p}_{\text {total }}$ & Qp2-3 & Qp $>3$ & $\mathbf{F}$ & PIg & $\mathbf{K}$ & $\mathbf{L}$ & $\mathbf{L m}$ \\
\hline Formación & Muestra & 205 & 90 & 53 & 37 & 115 & 64 & 51 & 90 & 81 & 9 & 98 & 10 \\
\hline La Boca miembro inferior & VH-3101 & 182 & 96 & 42 & 54 & 86 & 53 & 33 & 88 & 86 & 2 & 121 & 14 \\
\hline La Boca miembro inferior & VH-3102 & 79 & 51 & 22 & 29 & 28 & 11 & 17 & 171 & 171 & 0 & 142 & 1 \\
\hline La Boca miembro inferior & VH-3103 & 77 & 41 & 19 & 22 & 36 & 13 & 23 & 129 & 120 & 9 & 180 & 0 \\
\hline La Boca miembro inferior & VH-3104 & 189 & 152 & 87 & 65 & 37 & 12 & 25 & 98 & 80 & 18 & 203 & 10 \\
\hline La Boca miembro superior & VH-3108 & 252 & 159 & 102 & 57 & 93 & 24 & 69 & 9 & 8 & 1 & 100 & 17 \\
\hline La Joya & VH-3110 & 246 & 160 & 74 & 86 & 86 & 34 & 52 & 23 & 14 & 9 & 113 & 17 \\
\hline La Joya & VH-3111 & 257 & 172 & 97 & 75 & 85 & 31 & 54 & 40 & 30 & 10 & 67 & 17 \\
\hline
\end{tabular}

\begin{tabular}{|c|c|c|c|c|c|c|c|c|c|c|c|c|c|c|}
\hline & Parámetro & $\mathbf{L v}$ & Lvmi & Lvf & Lvl & LvTob. & Ls & Lsg & Lch & Lsf & Ch & HM & Micas & TOTAL \\
\hline Formación & Muestra & 73 & 45 & 26 & 2 & 0 & 15 & 4 & 3 & 8 & 2 & 2 & 2 & 399 \\
\hline La Boca miembro inferior & VH-3101 & 80 & 22 & 49 & 5 & 4 & 27 & 11 & 5 & 11 & 1 & 1 & 7 & 400 \\
\hline La Boca miembro inferior & VH-3102 & 99 & 58 & 36 & 4 & 1 & 42 & 1 & 1 & 40 & 1 & 3 & 4 & 400 \\
\hline La Boca miembro inferior & VH-3103 & 154 & 136 & 18 & 0 & 0 & 26 & 0 & 1 & 25 & 6 & 6 & 2 & 400 \\
\hline La Boca miembro inferior & VH-3104 & 153 & 113 & 14 & 11 & 6 & 40 & 40 & 0 & 0 & 0 & 4 & 1 & 499 \\
\hline La Boca miembro superior & VH-3108 & 65 & 60 & 5 & 0 & 0 & 18 & 13 & 0 & 5 & 25 & 8 & 6 & 400 \\
\hline La Joya & VH-3110 & 71 & 36 & 22 & 13 & 0 & 13 & 13 & 0 & 12 & 20 & 4 & 3 & 409 \\
\hline La Joya & VH-3111 & 31 & 26 & 5 & 0 & 0 & 17 & 17 & 0 & 2 & 21 & 13 & 2 & 400 \\
\hline
\end{tabular}

$\begin{array}{lll}\mathrm{Q} & = & \text { Total de granos de cuarzo } \\ \mathrm{Qm} & = & \text { Total de granos monocristalinos de cuarzo }=\mathrm{Qmr}+\mathrm{Qmo} \\ \mathrm{Qmr} & = & \text { Cuarzo monocristalino recto } \\ \mathrm{Qmo} & = & \text { Cuarzo monocristalino onduloso } \\ \mathrm{Qp} & = & \text { Total de granos policristalinos de cuarzo }=\mathrm{Qp} 2-3+\mathrm{Qp}>3 \\ \mathrm{Qp2-3} & = & \text { Grano policristalino de cuarzo con } 2-3 \text { unidades de cristal por grano } \\ \mathrm{Qp}>3 & = & \text { Grano policristalino de cuarzo con }>3 \text { unidades de cristal por grano } \\ \mathrm{F} & = & \text { Total de granos feldespáticos }=\mathrm{P}+\mathrm{K} \\ \mathrm{P} & = & \text { Feldespato sódico } \\ \mathrm{K} & = & \text { Feldespato potásico } \\ \mathrm{L} & = & \text { Total de granos líticos } \\ \mathrm{Lm} & = & \text { Total de granos líticos metamórficos }\end{array}$

Ingersoll (1992), a diferencia de los granos metamórficos que fueron identificados de acuerdo a Garzanti y Vezzoli (2003).

\subsubsection{Descripción petrográfica}

Las areniscas estudiadas varían en clasificación de componentes de moderada a buena. Las muestras se componen principalmente de cuarzo (monocristalino o policristalino, incluyendo pedernal), feldespatos, así como fragmentos volcánicos (con texturas felsíticas, microlíticas, tipo lathwork), fragmentos tobáceos y líticos metamórficos con texturas de metapelitas, metapsammitas/metafelsitas y metabasaltos. Los granos detríticos se alteran a sericita, asociada a la destrucción de minerales accesorios, líticos metamórficos y feldespatos por efecto de diagénesis. La composición de los líticos puede determinar el grado de redondez y la resistencia de las partículas que involucran a los procesos físico-químicos de la sedimentación.

Los minerales accesorios se clasifican entre ligeros y pesados. Dentro de los ligeros destaca la muscovita, que se encuentra como monomineral o, en ocasiones, en los fragmentos líticos metamórficos. Al igual que la muscovita, la biotita se presenta como monomineral o dominante en los granos líticos volcánicos. Adicionalmente, es

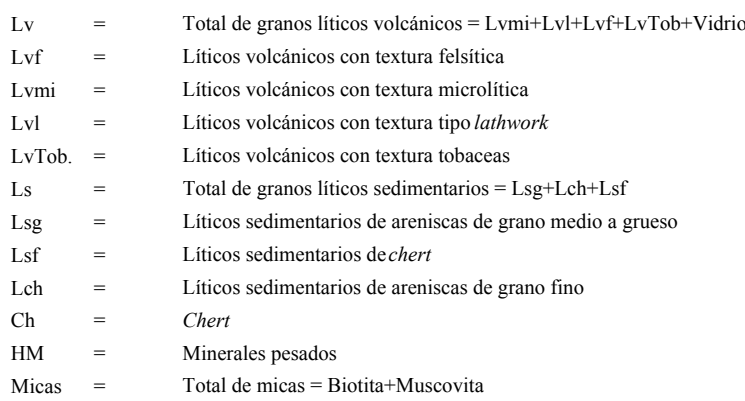

posible encontrar clorita, pero ha sido considerada como componente de fragmentos líticos de arenisca. Los minerales pesados accesorios comprenden zircón, rutilo y turmalina.

Generalmente, los granos tienen soporte de lodo y en algunos casos de grano, que en su mayoría son microlitos feldespáticos (Lvmi) desintegrados y alterados. Además, los efectos de diagénesis, alteración y silicificación hidrotermal post-deposicional pueden llegar a afectar las texturas originales de las muestras de la secuencia. Sin embargo, las texturas en las muestras representativas están bien preservadas para identificar la composición primaria de la roca. En algunos casos, la matriz es difícil de distinguir debido a la compactación y alteración de los componentes, en especial los líticos que formaron una pseudomatriz (Dickinson, 1970).

Con base en las metodologías empleadas para cuantificar y caracterizar cada uno de los componentes principales de las muestras de areniscas, se pudieron diferenciar dos petrofacies denominadas $P f 1$ y $P f 2$, que predominan de base a cima de la columna litoestratigráfica analizada. La $P f 1$ caracteriza al miembro inferior de la Formacion La Boca, mientras que la $P f 2$ domina en el miembro superior de La Formación La Boca y los lechos rojos de la Formación La Joya. Estas dos últimas unidades, por no presentar cambios 


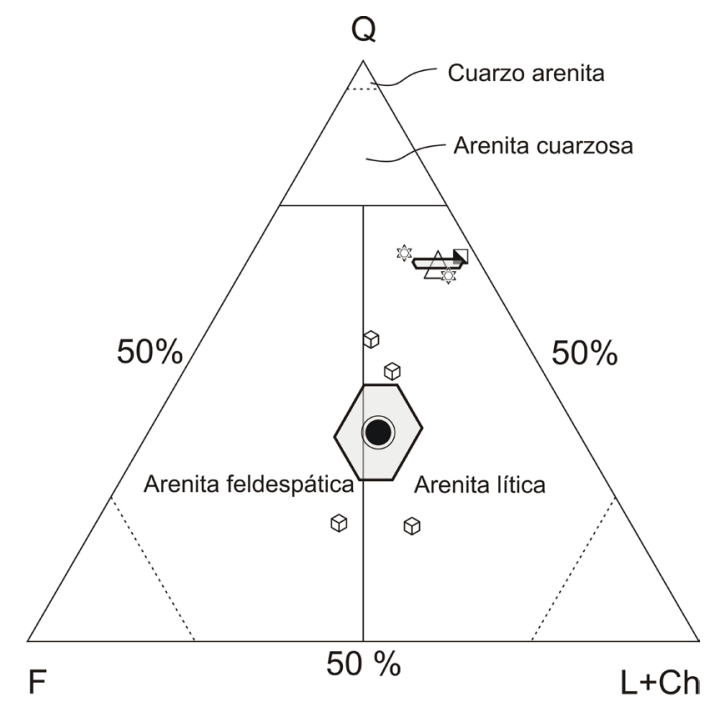

Leyenda

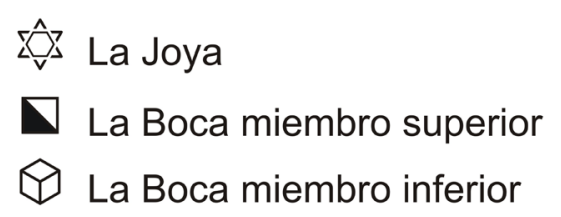

Figura 6. Composición modal de las areniscas de las Formaciones La Boca (unidades inferior y superior) y La Joya, en el diagrama QFL (Okada, 1971). Q: cuarzo; F: feldespatos; L+Ch: fragmentos líticos, incluido el pedernal (chert). Los polígonos representan la desviación estándar para las petrofacies $P f 1$ (círculo) y Pf2 (triángulo). Los centros de los polígonos representan la media aritmética (datos en las Tablas 3 y 4).

significativos en sus características petrográficas y por ende en su génesis, fueron consideradas en una sola petrofacies.

\subsubsection{Nomenclatura y clasificación de las areniscas}

De acuerdo al total de componentes $\mathrm{QF}(\mathrm{L}+\mathrm{Ch})$, siguiendo la clasificación de Okada (1971), las areniscas se caracterizan de manera muy heterogénea oscilando entre la arenita feldespática y una población predominante de arenita lítica (Figura 6).

Cuarzo. Utilizando el diagrama doble ternario (Qp23, Qmr, Qmo; Qp > 3, Qmo, Qm), propuesto por Basu (1976) y modificado por Tortosa et al. (1991), se distingue la abundancia y la posible procedencias del cuarzo en las muestras analizadas de las areniscas (Figura 7). El cuarzo más abundante es el monocristalino, que se presenta en su mayoría con morfologías subangulares a subredondeadas. Los granos de cuarzo presentan extinción ondulada o recta. El cuarzo policristalino se presenta con una extinsión ondulada, granos estirados o deformados y una morfología de grano subredondeada; con texturas de fábrica tectónica, que en ocasiones se confunde como pedernal $(\mathrm{Ch})$.

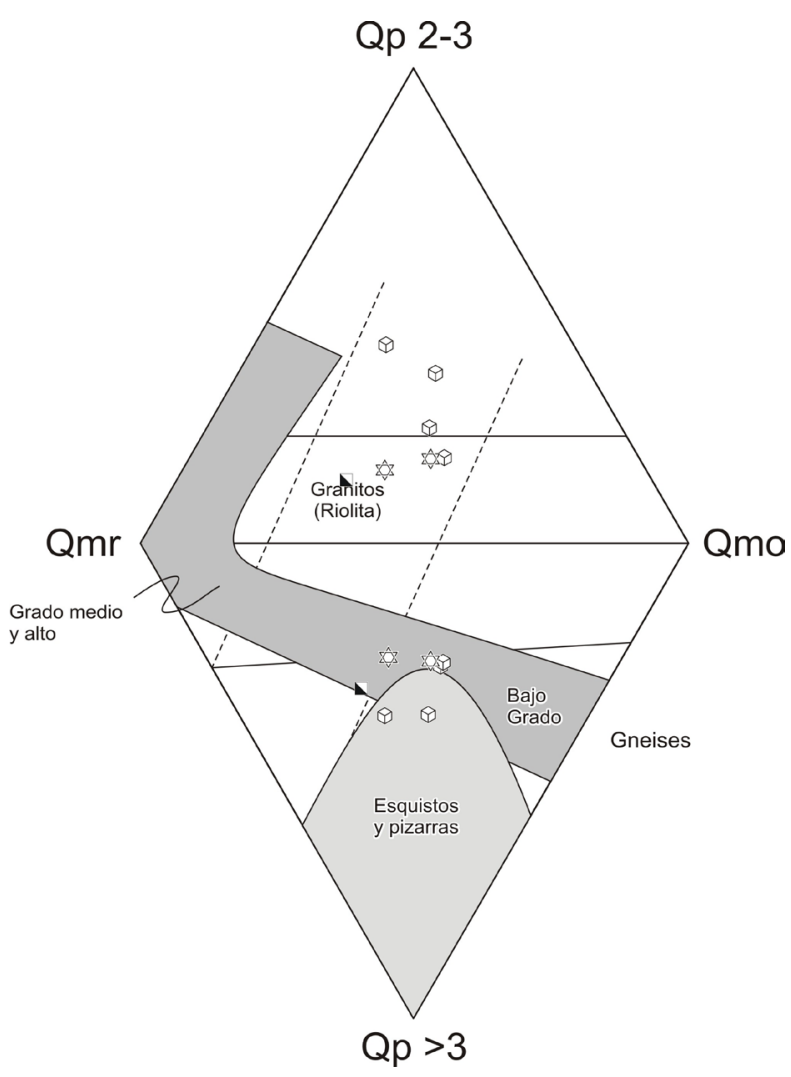

Figura 7. Clasificación de las areniscas de acuerdo a los tipos de cuarzo, según el diagrama de Basu et al. (1975) y modificado por Tortosa et al. (1991). Qmr: cuarzo monocristalino con extinción recta; Qmo: cuarzo monocristalino con extinción ondulante; Qp 2-3: cuarzo policristalino compuesto de dos o tres cristales; $\mathrm{Qp}>3$ : cuarzo policristalino compuesto de tres o más cristales.

Feldespatos. Los feldespatos mantienen un hábito euedral a subedral (Figuras $8 \mathrm{a}, \mathrm{b}$ ). Es posible distinguir dos tipos de feldespato: (a) feldespato potásico, con o sin maclado tipo Carlsbad y enrejado, y (b) plagioclasa, con su característico maclado polisintético, presente en una mayor proporción que el primer tipo. Predominantemente, la plagioclasa se encuentra truncada y/o alterada.

\section{Fragmentos líticos}

1) Líticos volcánicos. Los fragmentos líticos son el componente predominante de las areniscas, en especial los de tipo volcánico, con sus diferentes características texturales. Sin embargo, en la secuencia estudiada existen, en menor medida, los líticos sedimentarios y metamórficos (Figuras 8c-f y 9). Los fragmentos líticos volcánicos con textura microlítica (Lvmi; Figura 8c) predominan en las muestras (Tablas 3 y 4), y se presentan como granos que contienen microlitos de plagioclasa, soportados por una matriz devitrificada de color negro. Esta textura se asemeja a las reportadas por Fastovsky et al. (2005) y García-Obregón (2008) para basaltos-andesitas.

Como segundo grupo en abundancia (Tablas 3 y 4 ) destacan los fragmentos líticos félscos (Lvf; Figura 8d), que 

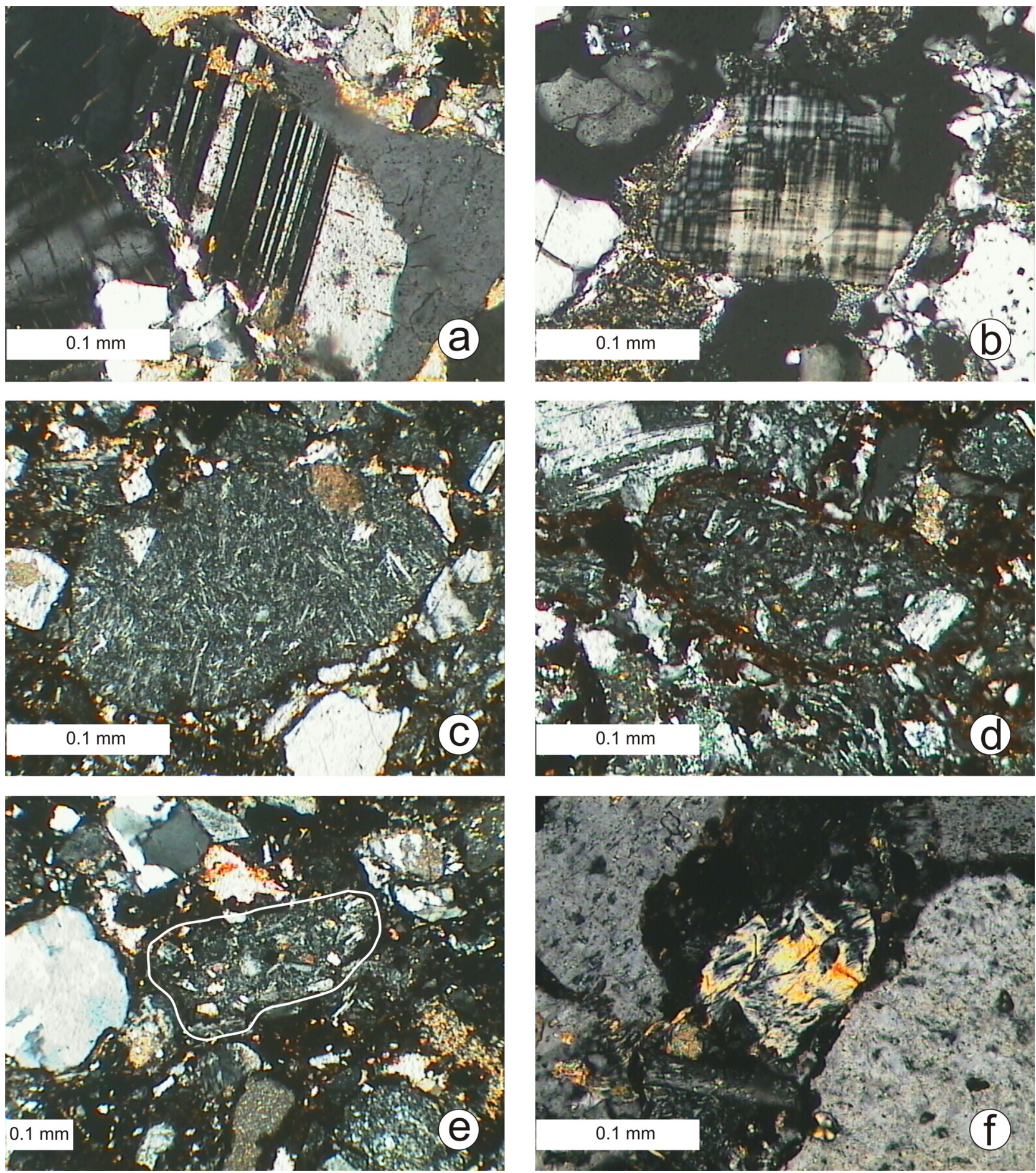

Figura 8. Fotomicrografías de areniscas de las Formaciones La Boca y La Joya. a) Muestra VH-3111, en donde se observa un cristal de plagioclasa con el típico maclado polisintético. b) Muestra VH-3108, en donde se observa un fragmento cristalino de microclina con doble sistema de maclado. c) Muestra VH-3102, con lítico volcánico microlítico (Lvmi). d) Muestra VH-3103, que presenta un lítico volcánico felsítico (Lvf). e) Muestra VH-3102, en donde se aprecia un lítico volcánico lathwork (Lvl). f) Muestra VH-3103, con lítico volcánico tobáceo.

consisten en cuarzo anedral y feldespatos, dispuestos en un mosaico microcristalino granular o seriado. En la mayoría de los casos, los Lvf contienen una fracción de material feldespático muy fino.

En una menor cantidad (Tablas 3 y 4) se presentan los fragmentos líticos tipo lathwork (Lvl; Figura 8e). Éstos están conformados por fragmentos de cristales de plagioclasas (laths; Dickinson, 1970) y otras partículas fenocristalinas de granulometría de tamaño de arena, en una masa intergranular, intersticial o devitrificada. $\mathrm{Al}$ igual 


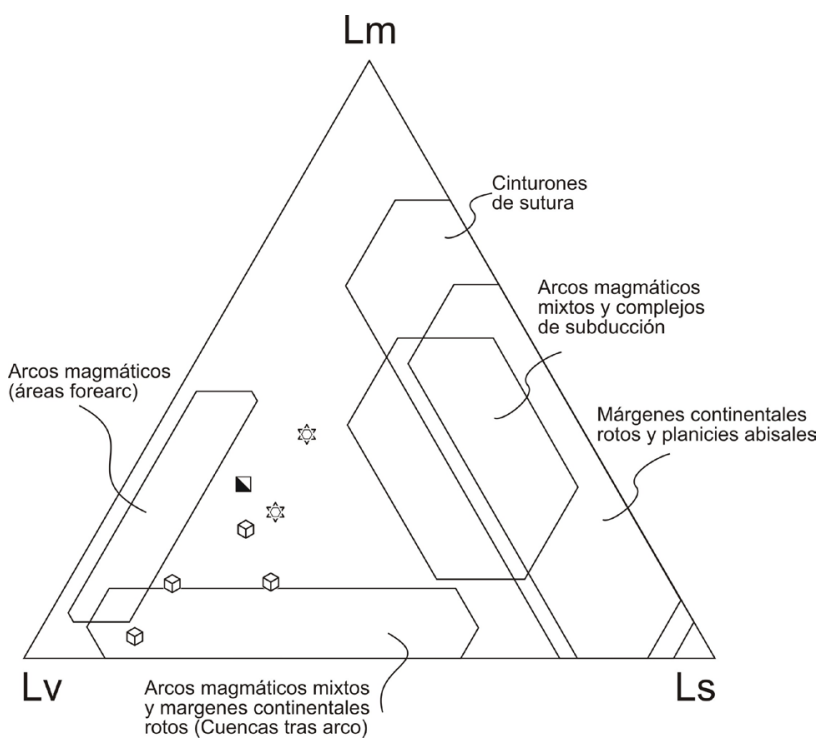

Figura 9. Diagrama ternario propuesto por Ingersoll y Suczek (1979), con campos definidos para ambientes tectónicos conocidos donde se muestra la composición de las areniscas jurásicas del valle de Huizachal. Lm: lítico metamórfico; Lv: lítico volcánico; Ls: Lítico sedimentario.

que las otras texturas, ésta se asemeja en gran medida a las reportadas previamente para las rocas volcánicas del valle de Huizachal (Fastovsky et al., 2005; García-Obregón, 2008).

2) Líticos metamórficos. Los granos de rocas metamórficas aun preservan relictos de la textura primaria de sus protolitos, lo que permitió identificar metapelitas, metapsammitas/metafelsitas y metabasaltos (Figuras 10bf). Los granos fueron discriminados según la metodología de Garzanti y Vezzoli (2003), por medio del índice de metamorfismo $(R M)$, identificado el grado de recristalización y deformación progresiva del clivaje (pizarrosidad) y esquistosidad.

Los fragmentos de rango $1(R M I)$ son predominantes y se presentan con clivaje y cristalización incipiente de micas. Los fragmentos de rango 2 (RM2) presentan fuerte realineación de la fábrica, migración de los bordes de cuarzo y generación de cristales de tipo acicular (spine-like structures; Frey, 1987). Los fragmentos tipo $R M 3$ muestran un desarrollo finito de esquistosidad con crecimiento de micas (e.g., en fragmentos metapsammíticos y metapelíticos, Figuras 10b, e, f). Con menor frecuencia se encontraron fragmentos de rango 4 ( $R M 4$ ), con crecimiento de cristales bien desarrollados de muscovita.

\subsubsection{Ambiente tectónico asociado a las areniscas}

En el diagrama triangular de Dickinson y Suczek (1979), basado en los parámetros QFL, las areniscas del valle de Huizachal se proyectan en los campos de arco transicional y orógeno reciclado (Figura 11). En contraste, en el diagrama triangular QmFLt (Dickinson et al., 1983) las muestras se distribuyen en los campos de arco disectado, arco transicional y orógeno reciclado (Figura 12). En el diagrama QmKP (Figura 13; Marsaglia, 1991) se observa una tendencia de incremento en el contenido de cuarzo de las areniscas hacia la cima de la secuencia, con una predominancia de plagioclasas sobre feldespatos potásicos. Esto se correlaciona con la presencia de un vulcanismo básico en el miembro inferior de la Formación La Boca, con el subsecuente cambio a vulcanismo ácido al ascender estratigráficamente.

El análisis petrográfico sugiere que las areniscas, derivadas de rocas relacionadas a un arco volcánico y en concordancia con los análisis directos de las rocas volcánicas, pueden ser informalmente divididas en las petrofacies $P f 1$ y $P f 2$. La $P f 1$ corresponde al miembro inferior de la Formación La Boca, mientras que la $P f 2$ agrupa las muestras del miembro superior de las Formaciones La Boca y La Joya. En esta última petrofacies se incluyeron muestras de dos formaciones (sin considerar edad alguna), debido a que no existen cambios sustanciales en las características composicionales detríticas.

La $P f 1$ se encuentra principalmente en la parte inferiormedia de la sucesión relacionada a vulcanismo y está caracterizada por tener un mayor contenido de líticos volcánicos que de líticos sedimentarios y metamórficos ( $\mathrm{Lm}_{12} \mathrm{Lv}_{67} \mathrm{Ls}_{20}$; ver Figura 9). Los líticos volcánicos se presentan subredondeados a redondeados en una matriz microlítica, con características texturales felsíticas, microlíticas, de tipo lathwork y ocasionalmente tobáceas $\left(\mathrm{Lvf}_{41} \mathrm{Lvmi}_{55} \mathrm{Lv}_{14}\right.$; Figura 14). En los diagramas QFL y QmFLt las muestras de la petrofacies Pf1 se despliegan en la parte inferior de los triángulos, en el campo de arco transicional y con composiciones de $\mathrm{Q}_{35} \mathrm{~F}_{30} \mathrm{~L}_{35}$ (Figura 11) y $\mathrm{Qm}_{22} \mathrm{~F}_{36} \mathrm{Lt}_{40}$ (Figura 12). La abundancia de plagioclasas es mayor que la de feldespatos potásicos $\left(\mathrm{Qm}_{37} \mathrm{P}_{60} \mathrm{~K}_{3}\right.$; Figura 13).

Por otra parte, la $P f 2$ está conformada por areniscas que se interestratifican en la parte media a superior con la sucesión volcánica. Respecto a los granos líticos, se destacan aquellos de origen volcánico $\left(\mathrm{Lm}_{30} \mathrm{Lv}_{49} \mathrm{Ls}_{21}\right.$; Figura 9) con texturas microlíticas $\left(\mathrm{Lvf}_{23} \mathrm{Lvmi}_{69} \mathrm{Lv}_{18}\right.$; Figura 14). Las plagioclasas son más abundantes que los feldespatos potásicos, aunque sus contenidos decrecen al aumentar el contenido de cuarzo monocristalino ( $\mathrm{Qm}_{88} \mathrm{P}_{9} \mathrm{~K}_{3}$; Figura 13). Estas muestras coinciden con aquellas que presentan un mayor índice de madurez textural, en comparación con la $P f 1$. Las areniscas de la $P f 2$ se grafican en el campo de arco disectado en el diagrama QmFLt, con valores de $\mathrm{Qm}_{59} \mathrm{~F}_{9} \mathrm{Lt}_{32}$ (Figura 12), y en el de orógeno reciclado, considerando el diagrama QFL (valores: $\mathrm{Q}_{69} \mathrm{~F}_{6} \mathrm{~L}_{25}$, Figura 11).

\section{Discusión}

El presente estudio es el resultado de la combinación de trabajo de campo y análisis de petrografía ígnea y sedimentaria, para proveer un esquema evolutivo de las 

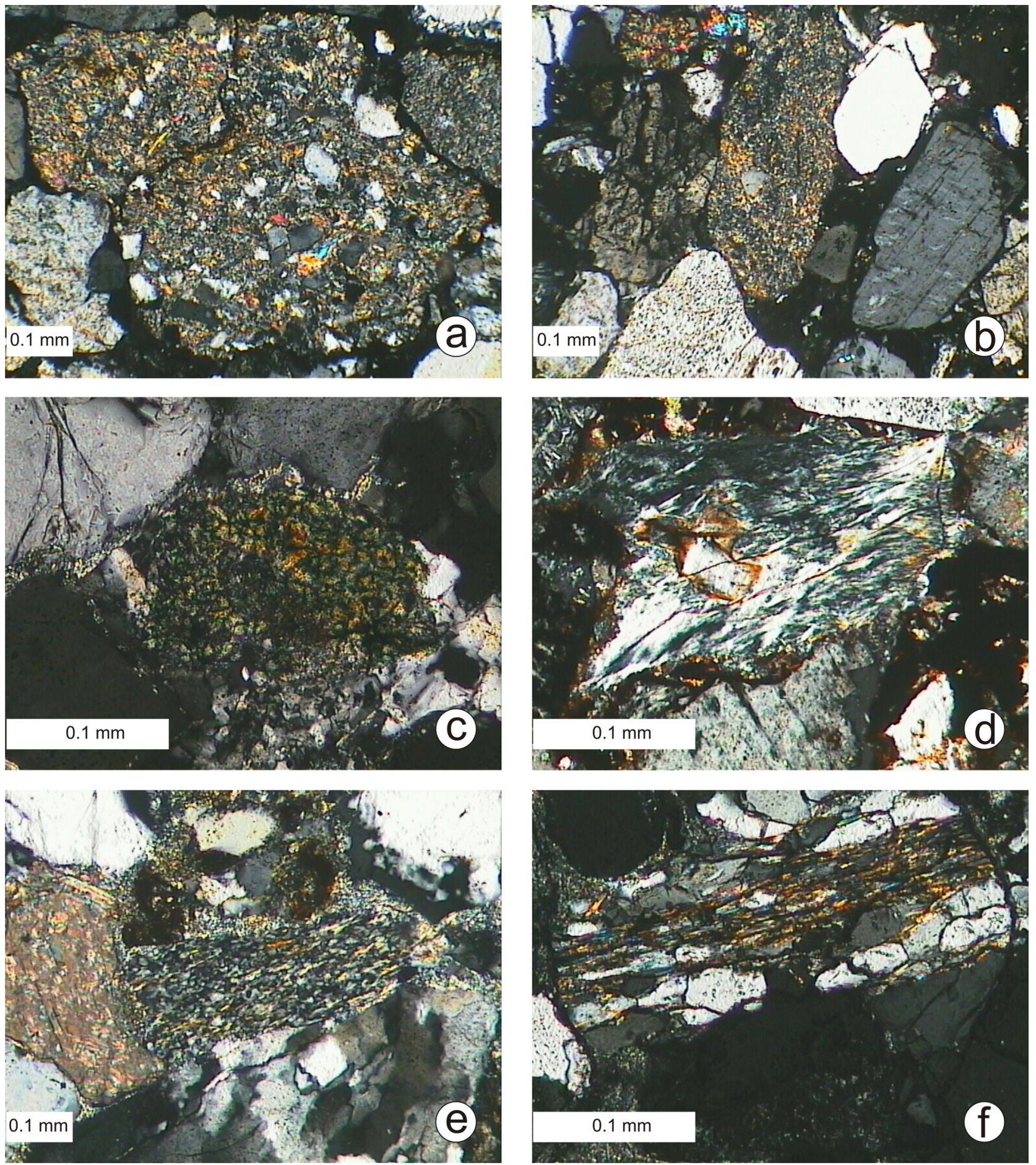

Figura 10. Fotomicrografías de areniscas de las Formaciones La Boca y La Joya. a) Muestra VH-3101, en donde se observa un lítico sedimentario (Lsp); b) Muestra VH-3101, con lítico metamórfico psammítico (Lmp) $R M 1$; c) Muestra VH-3108, lítico metabasáltico (Lmb) RM1; d) Muestra VH-3102, lítico metabasáltico (Lmb) RM2; e) Muestra VH-3108, lítico metamórfico felsítico (Lmf) RM2; f) Muestra VH-3111, lítico matamórfico felsítico (Lmf) $R M 3$. $R M(x)$ : índice de grado metamórfico para líticos, en donde x representa el valor o rango estimado observable de metamorfismo según las características petrográficas propuestas por Garzanti y Vezzoli (2003).

rocas clásticas jurásicas del valle de Huizachal, en el Noreste de México. Se aborda además el tema de procedencia de los lechos rojos continentales de las Formaciones La Boca (miembros Inferior y Superior) y La Joya. Se interpreta su composición, posible asociación con el arco jurásico instaurado al oeste de México (Barboza-Gudiño et al., 2008) y al posterior reciclaje de las unidades volcánicas y volcaniclásticas ya generadas, así como del basamento 


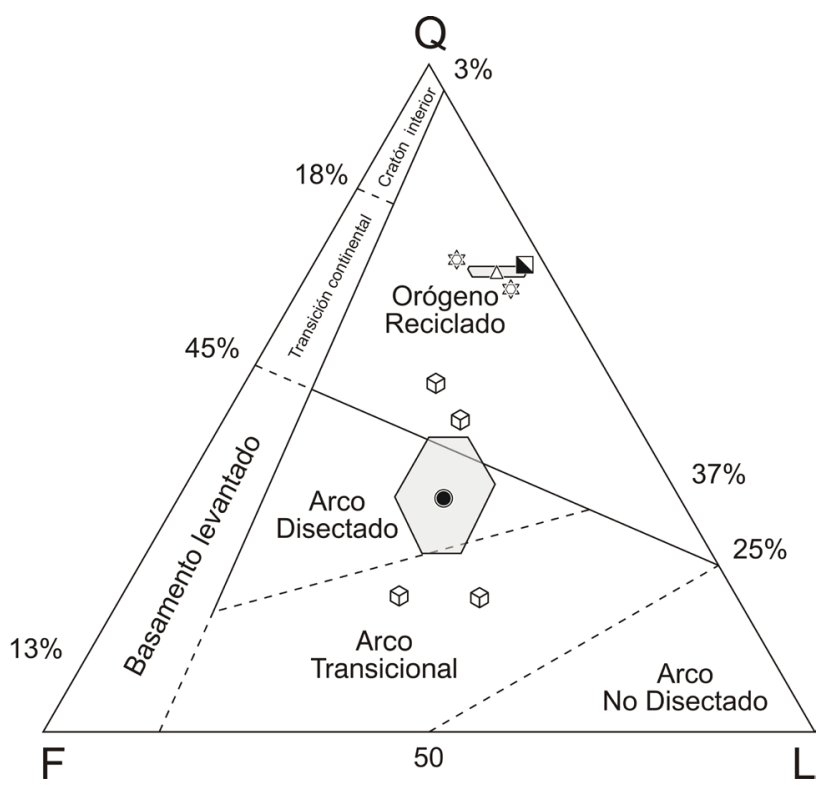

Figura 11. Diagrama ternario QFL propuesto por Dickinson y Suczek (1979), mostrando las características de procedencia de las areniscas del valle de Huizachal a partir de medias composicionales de areniscas provenientes de diferentes ambientes. Q: cuarzo total; F: feldespato total; L: total de líticos inestables. Los polígonos representan la desviación estándar para las petrofacies $P f 1$ (círculo) y $P f 2$ (triángulo). Los centros de los polígonos representan la media aritmética (datos en la Tabla 3). Para la leyenda, ver la Figura 6.

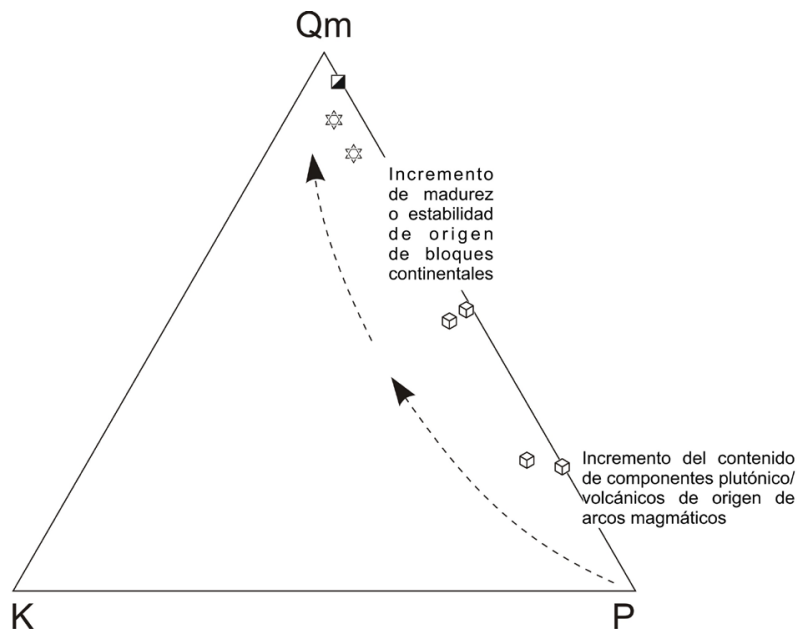

Figura 13. Diagrama ternario QmKP para las areniscas del valle de Huizachal. Q: cuarzo; K: feldespato potásico; P: plagioclasa.

cristalino precámbrico y paleozoico subyacente (TorresSánchez y Ramírez-Fernández, 2008). Es por esto que las areniscas del área de estudio presentan características petrográficas distintivas.

El uso de las características y parámetros petrográficos ha permitido establecer una nomenclatura para las areniscas,

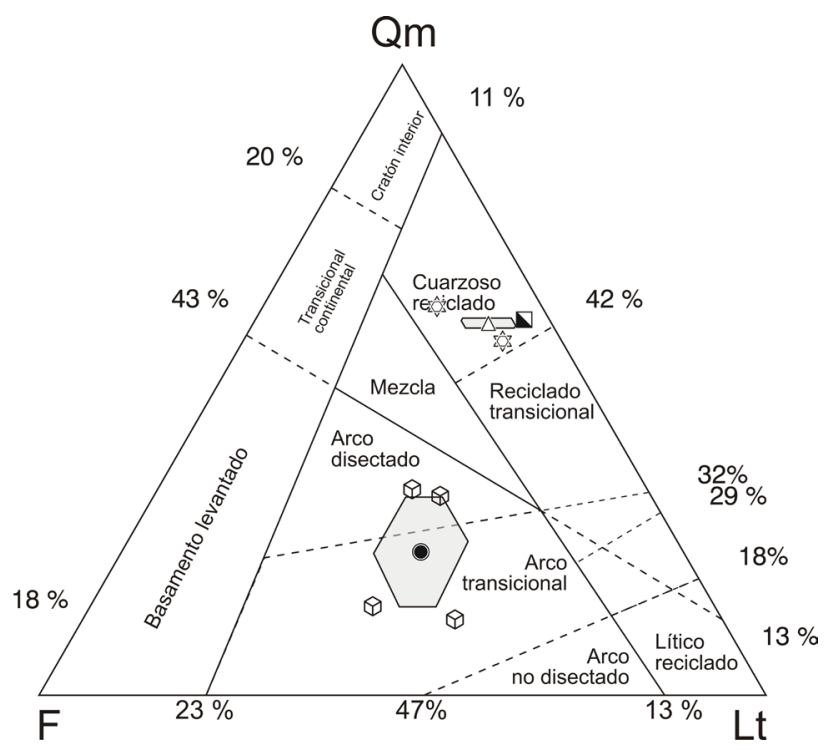

Figura 12. Diagrama ternario QmFLt propuesto por Dickinson et al. (1983) para las areniscas del valle de Huizachal. Qm: cuarzo monocristalino; F: feldespato total; Lt: total de líticos inestables. Los polígonos representan la desviación estándar para las petrofacies $P f l$ (círculo) y $P f 2$ (triángulo). Los centros de los polígonos representan la media aritmética (datos en la Tabla 3). Para la leyenda consultar la Figura 6.

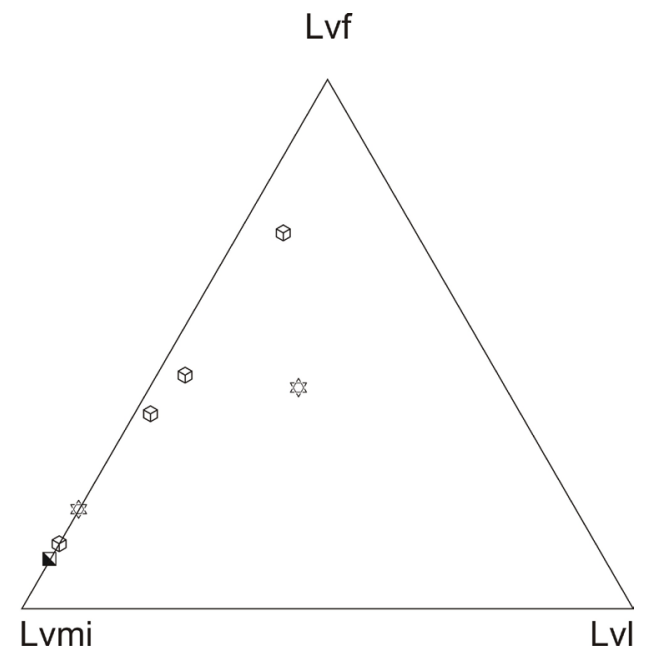

Figura 14. Diagrama triangular LvfLvmiLvl según Marsaglia e Ingersoll (1992), para las areniscas del valle de Huizachal. Lvf: lítico volcánico felsítico; Lvmi: lítico volcánico microlítico; Lvl: lítico volcánico lathwork.

así como una interpretación preliminar de su procedencia mediante diagramas ternarios con base en los componentes principales de la roca. Esto ha permitido la categorización de los resultados en dos petrofacies ( $P f 1$ y $P f 2$ ).

Los resultados petrográficos han demostrado la influencia directa de material derivado de rocas volcánicas 
$\mathrm{y}$, de acuerdo con las interpretaciones de la geología local, los efectos de un arco volcánico debieron de estar operando para influir en la composición de las areniscas. Lo anterior se fundamenta en la presencia de fragmentos líticos con texturas microlíticas y de tipo lathwork que sugieren una procedencia de rocas intermedias y básicas. El incremento de fragmentos felsíticos hacia la $P f 2$ (en especial el mimebro superior de la Formación La Boca) provee una señal de la disponibilidad félsica de la fuente y sugiere un aporte directo detrítico de microfenocristales de las riolitas reportadas para el área. Esto puede ser el resultado del cambio composicional del vulcanismo, de magmas primitivos a evolucionados. A diferencia de los demás fragmentos volcánicos, los de carácter tobáceo sugieren fuentes de composiciones riolíticas-tobáceas, como las que reportan Ramírez-Fernández et al. (2007) y García-Obregón (2008). De esta manera, los resultados son comparables con trabajos previos que han reportado la influencia de un arco volcánico jurásico en la sedimentación de los lechos rojos de edades jurásicas (Fastovsky et al., 2005; BarbozaGudiño et al., 2008).

Respecto a los líticos metamórficos, estos se presentan en mayor proporción hacia la parte media-superior de la secuencia analizada. Petrográficamente, es posible distinguir sus características de grado de metamorfismo $(R M)$ y asociarlas a las diferentes litologías que constituyen el basamento reportado. Los líticos metamórficos felsíticos y pelíticos/samíticos se asocian en particular a las litologías que constituyen al Esquisto Granjeno, mientras que el Gneis Novillo aparentemente sólo aporto fragmentos metamórficos felsíticos. Por otra parte los líticos metamórficos basálticos pueden provenir de los enjambres de diques que cortan al Gneis Novillo o bien de los cuerpos serpentiníticos contenidos en el Esquisto Granjeno. La presencia de minerales accesorios como rutilo, turmalina y zircón, valida la influencia directa del basamento en la composición de las areniscas. Esta asociación ha sido descrita previamente para el Esquisto Granjeno (Castillo-Rodríguez, 1988).

Rueda-Gaxiola et al. (1993a,b), Ramírez Fernández et al. (2007) y García-Obregón (2008) postularon la presencia de unidades de rocas triásicas en el valle de Huizachal. Sin embargo, los resultados obtenidos en el presente estudio indican que las areniscas de todos los niveles estratigráficos están influenciadas directamente por el vulcanismo que se ha asociado al arco jurásico del NE de México. Esto excluye la posibilidad de que las rocas clásticas del miembro inferior del valle de Huizachal tengan una edad triásica. Esto es más evidente si se compara petrográficamente la secuencia del valle de Huizachal con la que aflora en la localidad de Lomas de San Paulo Tranquitas (Galeana, Nuevo León; Michalzik, 1988; Rubio-Cisneros, 2008). Las rocas de esta última secuencia son de edad triásica (Barboza-Gudiño, 2008) y no presentan ninguna influencia del mencionado arco en los componentes principales de las areniscas.

\section{Conclusiones}

La secuencia que aflora en el valle de Huizachal comprende lechos rojos de la Formación La Boca, que puede ser dividida en dos miembros, que consisten de intercalaciones de material volcánico (flujos de lava), volcaniclástico (lahares, ignimbritas y otros tipos de tobas) y sedimentario (lutitas, limolitas, areniscas y conglomerados). El argumento para realizar ésta división se debe a la presencia de una fuerte discordancia angular. A la Formación La Boca le sobreyace, sobre una discordancia angularerosiva, la Formación La Joya. Esta consiste únicamente de rocas sedimentarias (conglomerados, limolitas y lentes de caliza).

Los lechos rojos de la Formaciones La Boca y La Joya representan ambientes de depósito de flujos de masa por gravedad afectados por vulcanismo sinsedimentario, que se relaciona a un régimen de arco durante el Jurásico Temprano. En general, la secuencia de la Formación La Boca incluye areniscas feldespáticas con abundancia en líticos volcánicos. Los cuarzos sugieren una procedencia de rocas graníticas (o bien su homólogo extrusivo riolítico) y rocas metamórficas de grado bajo-medio (procedentes del basamento del Anticlinorio Huizachal Peregrina).

Con base en el comportamiento de concentraciones de los componentes principales en las areniscas, estas se dividieron en dos petrofacies ( $P f 1$ y $P f 2)$. La $P f 1$ está representada por el miembro inferior de la Formación $\mathrm{La}$ Boca, y presenta poblaciones de líticos volcánicos con texturas felsíticas y composiciones basálticas a andesíticas. Las composiciones detríticas indican una procedencia de arco transicional a disectado. Los resultados del análisis petrográfico apoyan estas interpretaciones. En contraste la $P f 2$, que representa al miembro superior de la Formación La Boca y a la Formación La Joya, se ve controlada por líticos volcánicos con texturas microlíticas y un incremento en los líticos metamórficos de mayor grado. Las composiciones detríticas sugieren una fuente más diferenciada, a partir de la disminución de plagioclasas, afín a una procedencia de orógeno reciclado.

Un modelo de mezcla de detritos relacionados a un arcofuente (LmLvLs), descrito anteriormente, contrasta con un modelo tradicional de exhumación de un arco magmático, en el cual las divisiones del campo de arco magmático son consideradas en función de la cantidad expuesta del núcleo del protolito volcánico emplazado a lo largo del sistema de arco. El modelo primeramente se representa por la producción de areniscas con influencia de arco transicional y posteriormente, cuando la cubierta volcánica ha sido removida, se presentan areniscas con procedencia a partir de un arco disectado. Además, al paso del tiempo se observa un mayor aporte de material felsítico (Pfl $>$ Lvf) correlacionable con la evolución del arco magmático y un incremento en el contenido de líticos hacia la cima de la secuencia por el reciclaje de las secuencias subyacientes $(P f 2>$ Lvmi). Los fragmentos sedimentarios implican la 
erosión de rocas clásticas de las capas adyacentes y de posibles áreas de protolitos sedimentarios que se incluyen en el basamento subyacente.

Se considera que no sólo existen componentes derivados de la propia cubierta vulcano-sedimentaria, sino también en menor instancia de componentes metamórficos del basamento cristalino precámbrico y paleozoico. Por tal modo, se caracterizaron los líticos metamórficos, obteniendo rangos que van de medio a alto. Las rocas metamórficas fueron fraccionadas y clasificadas por transporte, interpretando su afinidad a esquistos psammíticos, pelíticos y gneises. Las potenciales áreas de procedencia para éste depocentro, que explicarían el contenido de líticos metamórficos y cuarzos policristalinos, pueden estar ligadas a la proximidad de ventanas expuestas del basamento, reciclaje y exhumación de los granitoides permo-triásicos, el Esquisto Granjeno del Paleozoico y el complejo del Gneis Novillo del Neoproterozoico.

Este modelo se traduce dentro del marco QFL y QmFLt entre un arco transicional ( $P f 1$, miembro inferior de la Formación La Boca) y un orógeno reciclado o basamento levantado $(P f 2$, miembro superior de la Formación La Boca y Formación La Joya). Este último estadio posiblemente esté ligado al levantamiento del basamento y a la exposición de las secuencias basales mesozoicas, debido a los movimientos extensionales por la apertura del Golfo de México hacia el Este.

La interpretación de la procedencia se ha basado en la medición de los componentes principales de las areniscas. La composición de las areniscas en el valle del Huizachal varía de base a techo, debido a la compleja historia tectónica de la región que involucra la presencia del basamento cristalino heterogéneo (Proterozoico-Paleozoico), sumado al régimen extensional por la apertura del Golfo de México y a la instauración de un arco volcánico jurásico.

\section{Agradecimientos}

Los autores agradecen a Y.Z. Ocampo Díaz, M. Martinez Paco, U. Jenchen y F. Velasco Tapia (Facultad de Ciencias de la Tierra, UANL), así como a T. Lawton (Universidad de Nuevo México), por su apoyo y aporte en las discusiones que mejoraron el presente trabajo. A J.T. Vázquez del Centro de Geociencias de la UNAM (Querétaro) por la elaboración de láminas delgadas. El presente trabajo fue financiado por el proyecto "Procesos magmáticos relacionados a diferentes etapas de la evolución de la Sierra Madre Oriental, NE de México", PAICyT-UANL clave CT1703-07, cuyo responsable fue el segundo autor, y por el Posgrado de la Facultad de Ciencias de la Tierra, UANL.

\section{Referencias}

Anderson, T.H., Silver, L., 2005, The Mojave Sonora megashear - Field and analytical Studies leading to the conception and evolution of the hypothesis, en Anderson, T.H., Nourse, J.A., McKee, J.W., Steiner, M.B., (eds.), The Mojave Sonora megashear hypothesis: Development, assessement, and alternatives: Geological Society of America Special Paper 393, 1-50.

Barboza-Gudiño, R., 2008, Detrital-zircon geochronology of Triassic fluvial and submarine fan deposits from northeastern Mexico: stratigraphy, paleogeography and tectonic implications (resumen), in Geological Society of America, annual meeting, Houston, Texas, Geological Society of America, Abstracts with Programs, 40, 197.

Barboza-Gudiño, J.R., Orozco-Ezquivel, M.T., Gómez-Anguiano, M., Zavala-Monsiváis, A., 2008, The Early Mesozoic volcanic arc of western North America in northeastern Mexico: Journal of South American Earth Sciences, 25, 49-63.

Barboza-Gudiño, J.R., Zavala-Monsiváis, A., Venegas-Rodríguez, G., Barajas-Nigoche, L.D., 2010, Late Triassic stratigraphy and facies from northeastern Mexico: Tectonic setting and provenance: Geosphere, 6, 621-640.

Barboza-Gudiño, J.R., Ramírez-Fernádez, J.A., Torres-Sánchez, S.A., Valencia, V.S., 2011, Geocronología de circones detríticos del Esquisto Granjeno en el Noreste de México: Boletín de la Sociedad Geológica Mexicana, 63, en prensa..

Bartolini, C., Wilson, J.L., Lawton, T.F., 1999, Mesozoic sedimentary and tectonic history of north-central Mexico: Geological Society of America Special Paper, 340, 1-380.

Basu, A., 1976, Petrology of Holocene fluvial sand derived from plutonic source rocks: implication to paleoclimatic interpretation: Journal of Sedimentary Petrology, 46, 694-709.

Basu, A., Young, S.W., Sutter, L.J., James, W.C., Mack, G.H., 1975, Reevaluation of the use of undulatory extinction and polycrystallinity in detrital quartz for provenance interpretation: Journal of Sedimentary Petrology, 45, 873-882.

Blatt, H., Christie, J.M., 1963, Udulatory extinction in quartz of igneous and metamorphic rocks and its significance in provenance studies of sedimentary rocks: Journal of Sedimentary Petrology, 33, 559-579.

Cameron, K.L., López, R., Ortega-Gutiérrez, F., Solari., L.A., Keppie, J.D., Schulze, C., 2004, U-Pb geochronology and $\mathrm{Pb}$ isotopic compositions of leached feldspars: constraints on the origin and evolution of Genville rocks from eastern and southern Mexico, en Tollo, R.P., Corriveau, L., McLelland, J., Bartholomew, M.J. (eds.), Proterozoic Tectonic Evolution of the Grenville Orogen in North America: Geological Society of America Memoir, 197, 755-769.

Carrillo-Bravo, J., 1961, Geología del Anticlinorio Huizachal-Peregrina al NW de Ciudad Victoria, Tamaulipas: Boletín de la Asociación Mexicana de Geólogos Petroleros, 13, 1-98.

Castillo-Rodríguez, H., 1988, Zur Geologie des kristallin Grundgebirges der Sierra Madre Oriental - insbesondere des Granjeno-SchieferKomplexes - in Südteil des Huizachal-Peregrina-Antiklinorium (Raum Ciudad Victoria, Bundesstaat Tamaulipas, Mexiko): Munster, Alemania, Westfälische Wilhelms-Universität Münster, Tesis de Maestría, $138 \mathrm{p}$.

Dickinson, W.R., 1970, Interpreting detrital modes of graywacke and arkose: Journal of Sedimentary Petrology, 40, 695-707.

Dickinson, W.R., Suczek, C., 1979, Plate tectonics and sandstone compositions: American Association of Petroleum Geologists Bulletin, 63, 2164-2182.

Dickinson, W.R., Beard, L.S., Brakenridge, G.R., Erjaves, J.L., Ferguson, R.C., Inman, K.F., Knepp, R.A., Lindberg, F.A., Ryberg, P.T., 1983, Provenance of North American Phanerozoic sandstones in relation to tectonic setting: Geological Society of America Bulletin, 94, 222-235. 
Dowe, D.S., Nance, R.D., Keppie, J.D., Cameron, K.L., Ortega-Rivera, A., Ortega-Gutierrez, F., Lee, J.W.K., 2005, Deformational history of the Granjeno Schist, Ciudad Victoria, Mexico: Constraints on the closure of the Rheic Ocean?: International Geology Review, 47, 920-937.

Fastovsky, D.E., Hermes, O.D., Strater, N.H., Bowring S.A., Clark, J.M., Montellano, M., Hernandez, R.R., 2005, Pre-Late Jurassic fossilbearing volcanic and sedimentary red beds of Huizachal Canyon, Tamaulipas, Mexico, en Anderson, T.H., Nourse, J.A, McKee, J.W., Steiner, M.B. (eds.), The Mojave-Sonora megashear hypothesis: development, assessment, and alternatives: Geological Society of America Special Paper, 393, 401-426.

Frey, M., 1987, Very low-grade metamorphism of clastic sedimentary rocks, en Frey, M. (ed.), Low temperature metamorphism: Glasgow, Blackie Academic and Profesional, 9-58.

García-Obregón, R., 2008, Cartografía geológica y petrología del vulcanismo mesozoico en el Valle de Huizachal, Tamaulipas: Linares, Nuevo León, México, Universidad Autónoma de Nuevo León, Tesis de Licenciatura, $113 \mathrm{p}$.

Garzanti. E., Vezzoli G, 2003, A classification of metamorphic grains in sands based on their composition and grade: Journal of Sedimentary Research, 73, 830-837.

Goldhammer, R.K., 1999, Mesozoic sequence stratigraphy and paleogeographic evolution, northeast Mexico, en Bartolini, C., Wilson, J.L., Lawton, T.F. (eds.), Mesozoic sedimentary and tectonic history of north-central Mexico: Geological Society of America Special Paper, 340, 1-58.

Goldhammer, R.K., Johnson C.A., 2001, Middle Jurassic-Upper Cretaceous paleogeographic evolution and sequence-stratigraphic framework of the northwest Gulf of Mexico rim: American Association of Petroleum Geologists Memoir, 75, 45-81.

Gómez-Anguiano, M., 2001, Cartografía geológica del área de San Juan de Matanzas en la porción noroccidental de la Sierra de Catorce, S.L.P. y correlación estratigráfica y geoquímica de rocas volcanogénicas del Noreste de México: Linares, Nuevo León, México, Universidad Autónoma de Nuevo León, Tesis de Maestría, 164 p.

Gradstein, F.M., Ogg, J.G., Smith, A.G., Bleeker, W., Lourens, L.J., 2004, A new Geologic Time Scale, with special reference to Precambrian and Neogene: Episodes, 27, 83-100.

Gursky, H.J., Michalzik, D., 1989, Lower Permian turbidites in the northern Sierra Madre Oriental, Mexico: Zentralblatt für Geologie und Palaeontologie, 5/6, 821-838.

Gursky, H.J., 1996, Paleozoic stratigraphy of the Peregrina Canyon, Sierra Madre Oriental, NE México: Zentralblatt für Geologie und Palaeontologie, 7/8, 973-989.

Ingersoll, R.V., 1990, Actualistic sandstone petrofacies: Discriminating modern and ancient source rocks: Geology, 18, 733-736.

Ingersoll, R.V., Suczek, C.A., 1979, Petrology and provenance of Neogene sand from Nicobar and Bengal fans, DSDP sites 211 and 218: Journal of Sedimentary Research, 49, 1217-1228.

Ingersoll, R.V., Bullard, T.F., Ford, R.L., Grimm, J.P., Pickle, J.D., Sares, S.W., 1984, The effect of grain size on detrital modes: a test of Gazzi-Dickinson point-counting method: Journal of Sedimentary Petrology, 54, 103-116.

Johnson, M.R., 1991, Sandstone petrography, provenance and plate tectonic setting in Gondwana context of the southeastern Cape-Karoo Basin: South African Journal of Geology, 94,137-154.

Keppie, J.D., Solari, L.A., Ortega-Gutiérrez, F., Ortega-Rivera, A., Lee, J.W.K., Lopez, R., Hames, W.E., 2004, U-Pb and 40Ar/39Ar constraints on the cooling history of the northern Oaxacan Complex, southern Mexico: tectonic implications, en Tollo, R.P., McLelland, J., Corriveau, L., Bartholemew, M.J. (eds.), Proterozoic Tectonic Evolution of the Grenville Orogen in North America: Geological Society of America Memoir, 197, 771-781.

Keppie, J.D., Dostal, J., Nance R.D., Miller, B.V., Ortega-Rivera, A., Lee, J.K.W., 2006, Circa 546 Ma plume-related dykes in the $\sim 1$ Ga Novillo Gneiss (east-central Mexico): Evidence for the initial separation of Avalonia: Precambrian Research, 147, 342-353.

Marsaglia, K.M., 1991, Provenance of sand and sandstone from a rifted continental arc, Gulf of California, Mexico, en Fisher, R.V., Smith,
G.A. (eds.), Sedimentation in Volcanic Settings: SEMP Special Publication, 45, 237-248.

Marsaglia, K.M., Ingersoll, R.V., 1992, Compositional trends in arc-related, deep-marine sand and sandstone: A reassessment of magmaticarc provenance: Geological Society of America Bulletin, 104, 1637-1649.

Michalzik, D., 1988, Trias bis teifste Unterkreide der nordöstlichsten Sierra Madre Oriental, Mexiko, Fazielle Entwicklung eines passiven Kontinentalrandes: Darmsatdt, Hesse, Alemania, Universidad Técnica de Darmstadt, Tesis Doctoral, 247 p.

Michalzik, D., 1991, Facies sequence of Triassic-Jurassic red beds in the Sierra Madre Oriental (NE Mexico) and its relation to the early opening of the Gulf of Mexico: Sedimentary Geology, 71, 243-259

Mixon, R.B., Murray, G.E., Díaz, G.T., 1959, Age and correlation of Huizachal Group (Mesozoic), state of Tamaulipas, Mexico: American Association of Petroleum Geologists Bulletin, 23, 757 771.

Nance, R.D., Fernández-Suárez, J., Keppie, J.D., Storey, C., Jeffries, T.E., 2007, Provenance of the Granjeno Schist, Ciudad Victoria, Mexico: Detrital zircon U-Pb age constraints and implication for the Paleozoic paleogeography of the Rheic Ocean, en Linnemann, U., Nance, R.D., Kraft, P., Zulauf, G. (eds.), The evolution of the Rheic Ocean: From Avalonian-Cadomian active margin to AlleghenianVariscan collision: Geological Society of America Special Paper, 423, 453-464.

Okada, H., 1971, Classification of sandstone: analysis and proposal: Journal of Geology, 79, 509-525.

Okulitch, V.A., 2002, Geological time chart: Ottawa, Canada, Geological Survey of Canada, Open-File Report 3040, 1 p.

Ortega-Gutiérrez, F., Ruiz, J., Centeno-García, E., 1995, Oaxaquia, a Proterozoic microcontinent accreted to North America during the late Paleozoic: Geology, 23, 1127-1130.

Ramírez-Fernández, J.A. García-Obregón, R., Velasco Tapia, F., Jenchen, U., de Leon Gomez, H., 2007, Bimodal volcanism in the Huizachal Valley and its relationship to the continental sedimentation during the rifting stage of the Sierra Madre Oriental in Mexico (resumen), en Geological Society of America, annual meeting, Denver, Colorado, EUA: Boulder, Colorado, EUA, Geological Society of America, Abstracts with Programs, 39, 19.

Rubio-Cisneros, I.I., 2008, Análisis geoquímico y petrográfico de areniscas de las Formaciones Huizachal y La Joya (Triásico Superior - Jurásico Inferior), NE de México: Linares, Nuevo León, México, Universidad Autónoma de Nuevo León, Tesis de Licenciatura, 121 p.

Rueda Gaxiola, J., López Ocampo, E., Dueñas, M.A., Rodríguez, J.L., 1993a, Los anticlinorios de Huizachal Peregrina y de Huayacocotla: Dos partes de la fosa de Huayacocotla - El Alamar: I. El Alogrupo Los San Pedros: Boletín de la Asociación Mexicana de Geólogos Petroleros, 43, 133.

Rueda Gaxiola, J., López Ocampo, E., Dueñas, M.A., Rodríguez J.L., Minero, M., Uribe, G. 1993b: Los anticlinorios de Huizachal Peregrina y Huayacoctla: Dos partes de la fosa de Huayacocotla El Alamar: II. Bioestratigrafía, cronoestratigrafía y paleoecología del Alogrupo Los San Pedro: Boletín de la Asociación Mexicana de Geólogos Petroleros, 43, $171 \mathrm{p}$.

Rueda-Gaxiola, J., López-Ocampo, E., Dueñas, M.A., Rodríguez J.L., Torres-Rivero, A., 1999, Palynostratigraphical method: Basis for defining stratigraphy and age of the Los San Pedros allogroup, Huizachal-Peregrina anticlinorium, Mexico, en Bartolini, C., Wilson, J.L., Lawton, T.F. (eds.), Mesozoic sedimentary and tectonic history of north-central Mexico: Geological Society of America Special Paper, 340, 229-269.

Salvador, A., 1987, Late Triassic-Jurassic paleogeography and origin of Gulf of Mexico Basin: American Association of Petroleum Geologists Bulletin, 71, 419-451.

Stewart, J.H., Blodgett, R.B., Boucot, A.J., Carter, J.L., López, R., 1999, Exotic Paleozoic strata of Gondwanan provenance near Ciudad Victoria, Tamaulipas, México, en Ramos, V.A., Keppie, J.D. (eds.), Laurentia-Gondwana connections before Pangea: Geological Society of America Special Paper, 336, 227-252. 
Torres, R., Ruiz, J., Patchett, P.J., Grajales, J.M., 1999, Permo-Triassic continental arc in eastern Mexico: tectonic implications for reconstructions of southern North America, en Bartolini, C., Wilson, J.L., Lawton, T.F. (eds.), Mesozoic sedimentary and tectonic history of north-central Mexico: Geological Society of America Special Paper, 340, 191-196.

Torres-Sánchez, S.A., Ramírez-Fernández, J.A., 2008, Basement of the Sierra Madre Oriental in NE Mexico: new field data of the Paleozoic Granjeno Schist in the Cañón de Caballeros area (resumen), en Geological Society of America, Joint annual meeting, Houston, Texas, EUA: Boulder, Colorado, EUA, Geological Society of America, Abstracts with Programs, 40, 254.

Tortosa, A., Palomares, M., Arribas, J., 1991, Quartz grain types in Holocene deposits from the Spanish Central System: some problems in provenance analysis, en Morton, A.C., Todd, S.P., Haughton, P.D.W. (eds.), Developments in Sedimentary Provenance Studies: Geological Society Special Publication, 57, 47-54.
Young, S.W., 1976, Petrographic textures of detrital polycristalline quartz as an aid to interpreting crystalline source rocks: Journal of Sedimentary Petrology, 46, 595-603.

Zhou, Y., Murphy, M.A., Hamade, A., 2006, Structural development of the Peregrina-Huizachal Anticlinorium, Mexico: Journal of Structural Geology, 28, 494-507.

Manuscrito recibido: Noviembre 5, 2009.

Manuscrito corregido recibido: Agosto 20, 2010.

Manuscrito aceptado: Septiembre 10, 2010. 